\title{
Una fosa-vertedero de época vettona en el Cerro de la Mesa (Alcolea de Tajo, Toledo)
}

\section{A Vettonian rubbish pit at the Cerro de la Mesa (Alcolea de Tajo, Toledo)}

\author{
Teresa Chapa Brunet (*) \\ Juan Pereira Sieso (**) \\ Ana Cabrera Díez (*) \\ Cristina Charro Lobato (*) \\ Marta Moreno-García (***)
}

\author{
Mónica Ruiz Alonso (***) \\ Sebastián Pérez Díaz (***) \\ José Antonio López Sáez (***) \\ Rafael Araujo (****)
}

\section{RESUMEN}

La existencia de fosas rellenas con tierra, cenizas, fragmentos cerámicos y fauna denominadas genéricamente como cenizales, basureros o vertederos, es un hecho bien conocido en la Meseta Norte durante la Segunda Edad del Hierro, vinculándose con los grupos Vacceos y Vettones. Sin embargo, su distribución debe ampliarse al occidente de la Meseta Sur y oriente extremeño, como se evidencia tanto en el Cerro de la Mesa como a través de indicios documentados en otros yacimientos más occidentales. Se presenta aquí un detallado estudio de un sector de la fosa que actuó como vertedero para la retirada de ciertos restos domésticos con ocasión de la reurbanización en profundidad del poblado vettón que tuvo lugar en la transición del siglo III al II a.C.

\section{ABSTRACT}

The existence of pits filled with earth, ashes, pottery fragments and fauna, usually known as ash pits, rubbish

(*) Departamento de Prehistoria, Facultad de Geografía e Historia, Universidad Complutense de Madrid. Av. Prof. Aranguren s/n. 28040 Madrid. España. Correos e.: tchapa@ghis.ucm.es; acabrera68@hotmail.com; cristinacharro@gmail.com

(**) Facultad de Humanidades de Toledo. Universidad de Castilla-La Mancha. Plaza de Padilla 4. 45071 Toledo, España. Correo e: Juan.Pereira@uclm.es

(***) Instituto de Historia. Centro de Ciencias Humanas y Sociales. CSIC. C/ Albasanz, 26-28. 28037 Madrid. España. Correos e.: marta.moreno@cchs.csic.es; monica.ruiz@cchs.csic.es; sebastian.perez@cchs.csic.es; joseantonio.lopez@cchs.csic.es

(****) Dpto. de Biodiversidad y Biología Evolutiva. Museo Nacional de Ciencias Naturales. CSIC. C/ José Gutiérrez Abascal 2. 28006 Madrid. Correo e.: rafael@mncn.csic.es

Recibido 11-VII-2012; aceptado 12-II-2013. pits or dumps, has been recognized on many Second Iron Age settlements of the Spanish Northern Plateau, generally linked with Vaccean and Vettonian groups. However, its distribution should be extended to the west of the Southern Plateau and eastern Extremadura, as evidenced by the example of the Cerro de la Mesa village and indications coming from other western sites. We offer here a detailed study of part of a rubbish pit where certain domestic remains were withdrawn in connection with a new project of urbanisation of the Vettonian village held on the transition from the $3^{\text {rd }}$ to the $2^{\text {nd }}$ centuries $B C$.

Palabras clave: Iberia; Meseta Sur; Segunda Edad del Hierro; Vettones; Fosas vertederos; Cenizales.

Key words: Iberia; Southern Meseta; Second Iron Age; Vettons; Trash pits; Ash pits.

\section{CARACTERÍSTICAS DEL YACIMIENTO}

El Cerro de la Mesa se localiza en el límite entre las comarcas de La Campana de Oropesa y La Jara, al oeste de la provincia de Toledo. Se sitúa en la margen derecha del río Tajo (Fig. 1), que capta en esta zona dos afluentes principales: el Gévalo, unos $11 \mathrm{~km}$ aguas arriba, y el Huso, procedente del sur y cuya confluencia se produce frente al yacimiento. Administrativamente pertenece al municipio de Alcolea de Tajo, y se encuentra próximo a la pedanía de El Bercial (coordenadas UTM X30321472; Y304405158). La elevación marca la frontera entre una exten- 
sa zona de afloramientos graníticos al sur y los conjuntos de terrazas y depósitos de arenas arcósicas y conglomerados del Paleógeno y Mioceno hacia el norte (1). Esta localización estratégica, que permite disponer tanto de pastos como de tierras agrícolas, se refuerza con la existencia de un vado que tuvo un tránsito importante desde la Prehistoria hasta el siglo XIV d.C., cuando el Arzobispo Pedro Tenorio construyó el puente que dará nombre a la actual población de Puente del Arzobispo, situando aguas abajo el cruce obligado del río (Chapa y Pereira 2006).

La superficie del Cerro ha sufrido importantes transformaciones recientes (Fig. 2), por la construcción del Embalse de Azután (1969), perteneciente a la Confederación Hidrográfica del Tajo (CHT) y con el que se asocian dos centrales eléctricas gestionadas por la empresa Iberdrola. El yacimiento se sitúa en terrenos de carácter público. El área protegida, en torno a 1,5 ha, supone casi un tercio de la extensión original del área intramuros. Aunque la construcción de la presa afectó directamente a la superficie del Cerro solo en 1991 J. L. Miranda Valdés, ingeniero de la CHT, informa sobre la detección de un tramo de muralla, durante los trabajos de explanación y zanjeo para el sistema de regadío en el término de Alcolea de Tajo. A partir de este momento comienzan las primeras intervenciones arqueológicas que documentan y excavan parcialmente el sector de la muralla. En 1999 se decide iniciar excavaciones sistemáticas, ante la propuesta del Ayuntamiento de asociar a ellas de manera permanente un Módulo de Formación y Empleo. Los trabajos serán codirigidos en esta primera campaña por J. J. Cano Martín y J. Ortega Blanco, continuando este último como director en los trabajos que se prolongaron, con interrupciones, hasta 2003. En esta etapa se excavaron diferentes sectores del yacimiento con interesantes resultados (Almagro et al. 1999; Ortega y Valle 2004), pero sin que llegara a redactarse una memoria de carácter general. A partir de 2004 se encargó a dos de nosotros (Juan Pereira y Teresa Chapa) la reanudación de las excavaciones sistemáticas, siempre asociadas al citado Módulo, conforme a

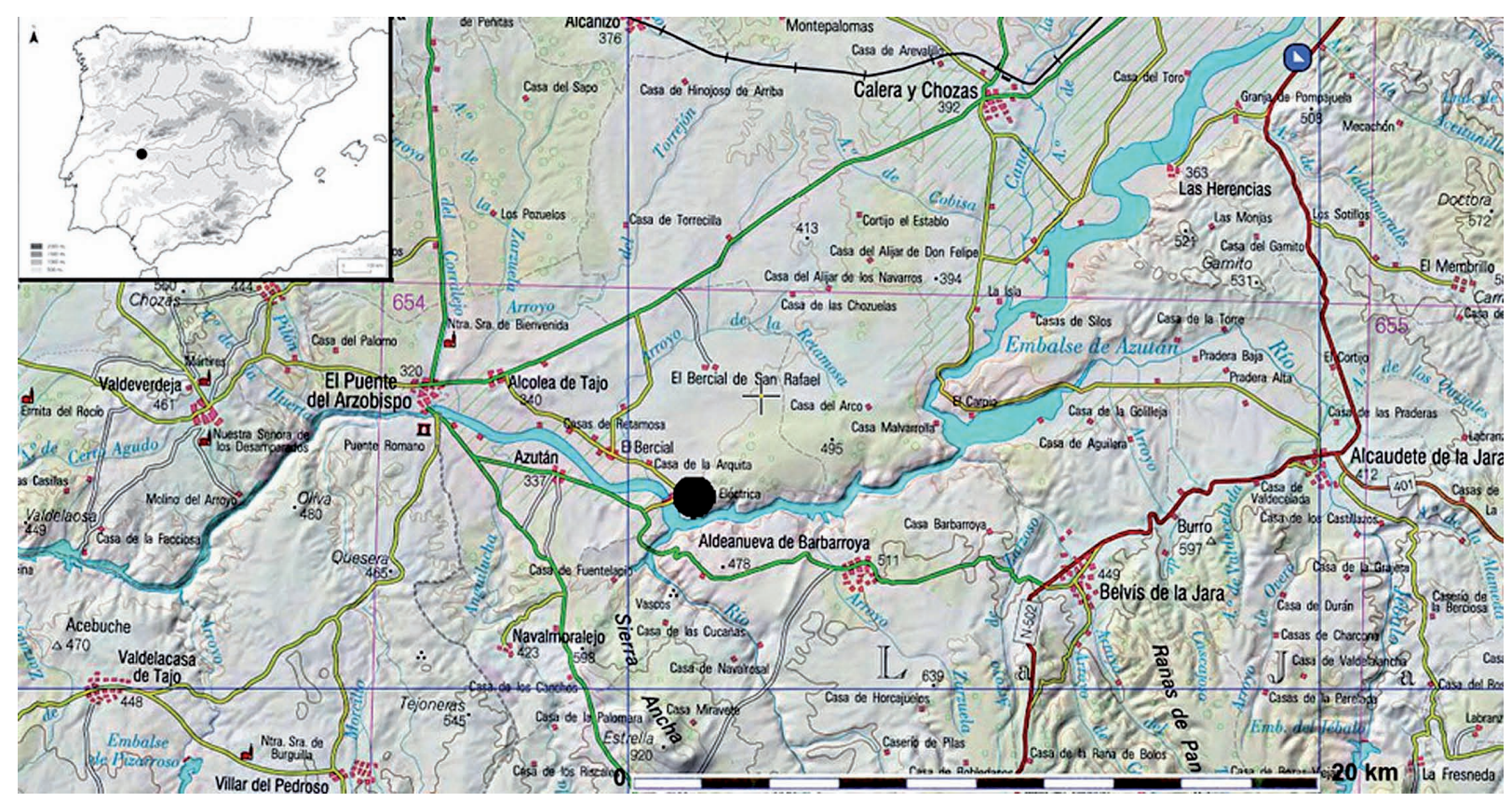

Fig. 1. Localización del Cerro de la Mesa. Cartografía: Instituto Geográfico Nacional MTN 1000.

(1) MAGNA 50, Hoja 654: Puente del Arzobispo. 


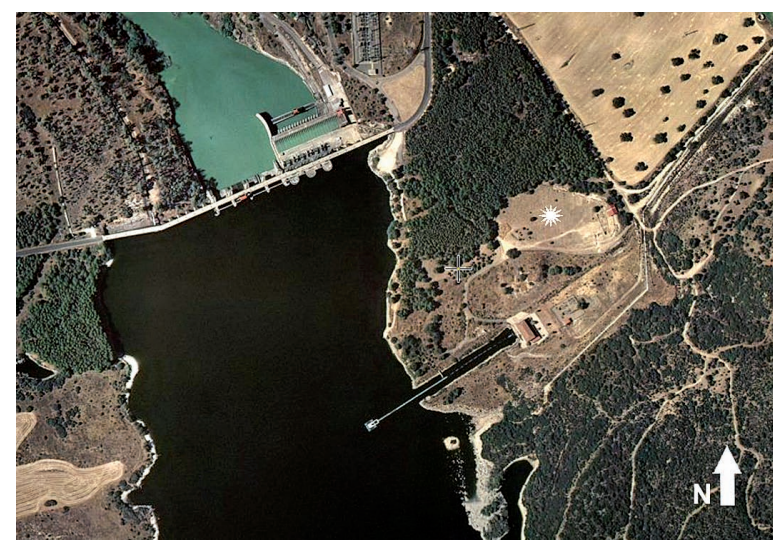

Fig. 2. Vista aérea del Cerro de la Mesa junto a la presa del embalse de Azután (Alcolea de Tajo, Toledo).

la planificación desarrollada por la Dirección General de Patrimonio de Castilla la Mancha. Estas excavaciones han continuado hasta 2010.

\section{UNIDADES ARQUEOLÓGICAS PRINCIPALES}

Entre 1999 y 2010 se han localizado diversas estructuras arqueológicas, siempre dentro del área reservada (Chapa y Pereira 2006; Charro et al. 2009) (Fig. 3):

a) Muralla: circunda la parte superior del cerro, y en ciertas zonas conserva una altura de hasta $3 \mathrm{~m}$. Su excavación tuvo lugar fundamentalmente en las campañas de 1999, 2000 y 2003. Las características de su muro en talud, reforzado con torreones semicirculares, han permitido proponer una fecha en torno al siglo VII a.C. para su construcción. Su final se produciría a inicios del siglo VI a.C. cuando sitúan el posible santuario emplazado al sur del poblado. Sus excavadores plantearon incluso la existencia de un muro de fecha anterior, del que apenas pudieron obtenerse datos. En la Segunda Edad del Hierro se hicieron trabajos de reconstrucción y refuerzo mediante paramentos de perfil vertical y torreones de planta cuadrada (Ortega y Valle 2004: 177).

b) Zona de posible santuario. Su excavación corresponde a la campaña de 2003 (Ortega y Va1le 2004: 178-179), identificándose dos estancias separadas por un pequeño tabique de adobe. En una de ellas se localizó un hogar rectangular de esquinas ligeramente extendidas, por lo que se ha incluido en la serie conocida como "altares de piel de toro" o de tipo "lingote chipriota". En estos espacios se recuperó un vaso a mano de cuello acampanado y grandes dimensiones, semejante a los de Casa del Carpio (Pereira 2008: 198) y al menos dos anforoides con decoración pintada, asociados a cuencos de cerámica gris que les servirían de tapadera. Su pavimento amortizaba la superficie arruinada de la muralla del siglo VII a.C. El vaso acampanado fue fechado en el siglo VII a.C., y el resto de las piezas a inicios del siglo VI a.C., aunque la cronología de estas, por paralelos en otros yacimientos, podría rebajarse hasta fines de la centuria o inicios de la siguiente (vide infra).

c) El poblado vettón. En diversas campañas se excavó en toda la extensión del frente oriental intramuros del poblado, visualizando una serie de casas rectangulares, compartimentadas con algunas reorganizaciones puntuales (Almagro-Gorbea et al. 1999; Ortega y Valle 2004: 177-182). En las campañas recientes se han excavado dos viviendas con acceso empedrado, situadas en el frente sur y fechables en el siglo II a.C. (Chapa et al. 2007).

d) La fosa-vertedero, subyacente a las viviendas vettonas, se extiende por el cuadrante sureste del yacimiento con una profundidad de más de 2 $\mathrm{m}$. Su estudio es el objetivo del presente trabajo.

\section{LA FOSA-VERTEDERO}

Durante los trabajos de limpieza superficial asociados a las recientes campañas de excavación aparecían capas arcillosas y cenicientas con abundantes restos de fauna bajo los suelos de las casas vettonas. Dos de los cortes de la campaña de 2003 abiertos al interior de la zona sur de la muralla, revelaban una sucesión de niveles con gran cantidad de fragmentos de cerámica, pizarras, carbones, huesos y conchas. En un primer momento barajamos su interpretación como un depósito vinculado a las ceremonias desarrolladas en la zona del altar, pero conforme avanzó la excavación comprobamos que era una enorme zona excavada en época posterior, donde se acumularon progresivamente desechos de diverso tipo. 


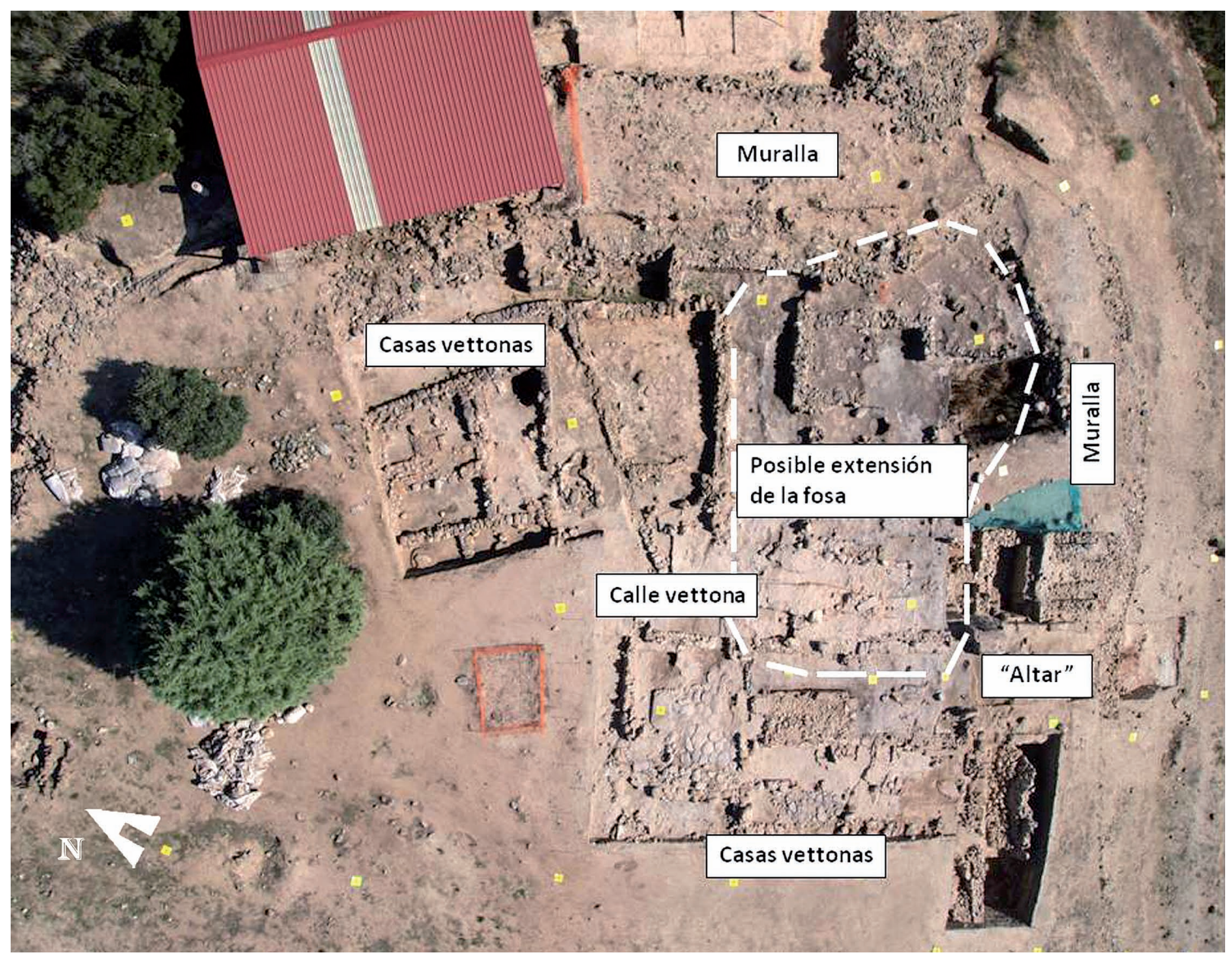

Fig. 3. Unidades arqueológicas reconocidas en el Cerro de Mesa (Alcolea de Tajo, Toledo): muralla, altar, viviendas vettonas y fosa-vertedero. La línea indica su posible extensión.

La extensión de la fosa solo puede determinarse de forma aproximada, puesto que subyace a estructuras del hábitat vettón que impiden delimitarla con seguridad. El área que proponemos está confirmada por la aparición bajo el suelo o los muros de las viviendas de los típicos niveles cenicientos con los componentes antes citados, pero podría ser mayor. Su profundidad en el área excavada alcanzaba $2,20 \mathrm{~m}$, pero seguramente tuvo un fondo irregular, dependiendo de la altura y solidez de las estructuras que encontrara en su base. Por tanto, solo podemos hacer un cálculo de mínimos muy prudente, tomando como media $1,5 \mathrm{~m}$ de profundidad y $134 \mathrm{~m}^{2}$ de superficie, lo que nos daría como resultado un volumen en torno a $200 \mathrm{~m}^{3}$.
El área excavada aprovecha uno de los cortes de 2003, correspondiente al lado norte de la cuadrícula vecina a aquella donde se encontró el altar. Sabemos que la fosa comenzó a excavarse sobre los adobes que separaban las dos estancias, ya que esta acción quedó reflejada en el testigo correspondiente a esa campaña (Fig. 4). Los trabajos arqueológicos extrajeron entonces una parte del relleno de la fosa, en este corte y en otro situado más al Este, pero desconocíamos los resultados obtenidos. Por ello consideramos necesario realizar una ampliación durante los trabajos de campo desarrollados en 2010.

La excavación se llevó a cabo mediante niveles artificiales, ya que la sedimentación era muy uniforme, $\mathrm{y}$ aunque se apreciaban a veces pequeños 


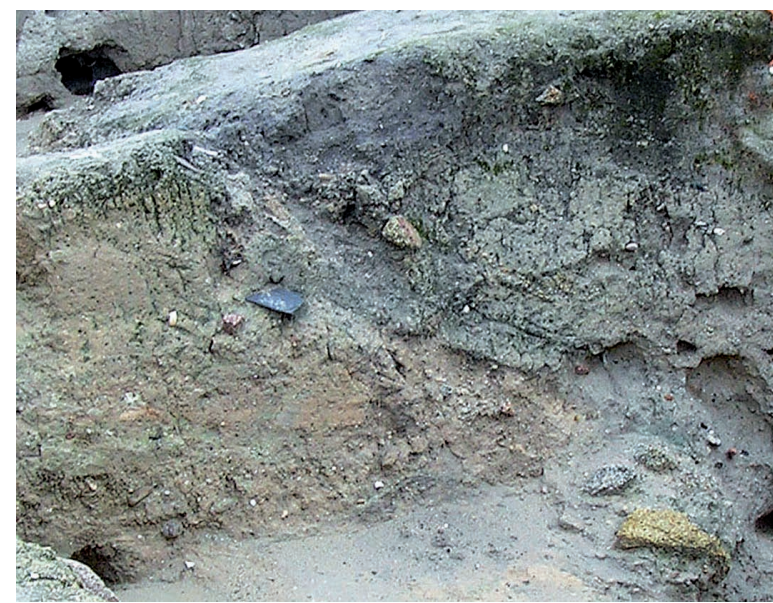

Fig. 4. Excavación de la fosa cortando los adobes del área del posible santuario.

lentejones o bolsadas, resultaba difícil aislarlos por su escasa diferenciación respecto al resto. El contenido era invariablemente de fragmentos cerámicos, pizarras, carbones, fauna de diverso tipo y algunas otras piezas elaboradas, como dos mangos de hueso, pero sin apenas restos metálicos. Todo ello se integraba en una matriz de tierra más o menos cenicienta, que muy ocasionalmente parecía incluir algunos vestigios constructivos, como piedras, restos de adobe o las propias pizarras. Algunos orificios revelaban la incidencia de madrigueras o nidos de abejaruco, que intentamos minimizar en la limpieza inicial del frente de corte (Fig. 5).

Hemos dividido el depósito en 6 niveles de espesor más o menos similar, salvo los dos más profundos, que conforman una transición con las tierras arcillosas compactas del fondo de la fosa.

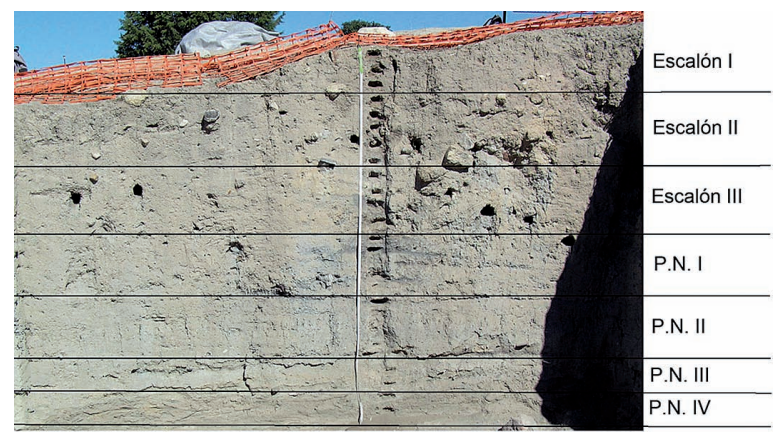

Fig. 5. Perfil de la fosa-vertedero con indicación de los niveles de excavación.
El nivel más superficial (Escalón I) se ha desechado para este estudio, ya que su grosor era muy irregular y estaba afectado por la construcción de una calle de época vettona, inmediatamente superpuesta a él. En la base de la fosa se pudo documentar un nuevo nivel, este ya in situ, con estructuras domésticas que por sus materiales parecen corresponder a un asentamiento del siglo $\mathrm{V}$ a.C. (Fig. 6). Los dos niveles superiores (Escalón II y III, UEs 604 y 606) constan de una mayor superficie excavada, al corresponderse con la anchura de la superpuesta calle vettona, mientras que los denominados como PN (Perfil Norte) 1 a 4 corresponden a la profundización de este corte en una extensión más reducida (Tab. 1).

\section{DATACIONES}

Al estudiar y analizar los restos arqueológicos y polínicos de los niveles artificiales de la fosa se seleccionaron muestras asociadas a la columna polínica y constituidas por macrorrestos de carbón. Los resultados facilitaron una referencia cronológica para Escalón III, PN 1, PN 2 y PN 3. Durante su discusión e interpretación se decidió una nueva selección de muestras, en este caso procedentes de la colección faunística de la especie Cervus para completar el desarrollo de Estrato III, así como Estrato II y PN 4. Desafortunadamente la muestra de un astrágalo de Cervus procedente del Estrato II no contenía el suficiente colágeno para ser datado.

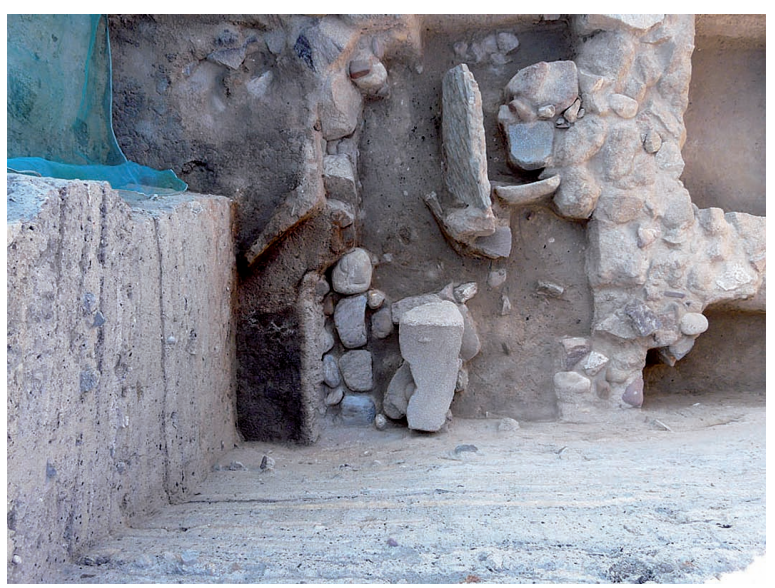

Fig. 6. Nivel de hábitat del siglo V a.C. bajo la fosa-vertedero. En primer término se aprecia un molino de mano de superficie cóncava con un tope en su zona proximal.

Trab. Prehist., 70, N. ${ }^{\circ}$ 1, enero-junio 2013, pp 140-165, ISSN: 0082-5638

doi: $10.3989 /$ tp.2013.12106 


\begin{tabular}{|l|c|c|}
\hline \multicolumn{1}{|c|}{ Niveles } & $\begin{array}{c}\text { Espesor } \\
(\mathbf{c m})\end{array}$ & $\begin{array}{c}\text { Superficie } \\
\left(\mathbf{m}^{\mathbf{2}} \mathbf{)}\right.\end{array}$ \\
\hline Escalón II $+604+606$ & 43 & 16,09 \\
\hline Escalón III + 604 +606 & 40,6 & 15,71 \\
\hline Perfil Norte 1 & 38,1 & 4,53 \\
\hline Perfil Norte 2 & 40,6 & 4,53 \\
\hline Perfil Norte 3 & 27,5 & 4,53 \\
\hline Perfil Norte 4 & 30 & 4,53 \\
\hline
\end{tabular}

Tab. 1. Relación del espesor y la superficie de cada nivel del Cerro de la Mesa.

La tabla 2 muestra las dataciones de ${ }^{14} \mathrm{C} \mathrm{ob-}$ tenidas en la secuencia de la fosa-vertedero, con sus correspondientes fechas calibradas cal BC a 2 sigma $(95,4 \%$ probabilidad) utilizando el software CALIB 6.0 (Stuiver y Reimer 1993). En su conjunto, salvo la datación de la muestra superior $(100 \mathrm{~cm})$, se solapan entre ellas a lo largo de sus respectivos intervalos de calibración, en un marco cronológico ca. 810-405 cal BC, con tres rangos de mayor probabilidad ca. 530-510, 615600 y 760-700 cal BC. En su mayoría proceden de la datación de macrocarbones, pero incluso la realizada a $220 \mathrm{~cm}(\mathrm{PN} 3)$, sobre un material de vida corta (falange de ciervo), arroja un rango de calibración de casi cuatro siglos, entre los siglos VIII y V cal BC (762-416 cal BC). Ello es debido a la "meseta" que hay esta parte de la curva de calibración, que no permite mayor precisión (López Sáez y Blanco González 2005; López Sáez et al. 2008). La datación de la muestra a $100 \mathrm{~cm}$, en el techo del Escalón III, sobre un metacarpo de ciervo, a diferencia de las anteriores (incluida la de la base de este mismo escalón a $120 \mathrm{~cm}$ ), arroja una calibración de la segunda mitad del I milenio: ca. 390-207 cal BC. Toda la secuencia encaja cronológicamente con los contextos de la Primera $(850-400$ cal BC) y Segunda Edad del Hierro (400-205 ca BC) de la región vettona (Álvarez Sanchís 2003).

\section{MATERIALES CERÁMICOS}

El número de fragmentos cerámicos, sus características esenciales y su peso se muestran en la tabla 3 en cantidades absolutas, y porcentualmente en la tabla 4. Si consideramos al Escalón II como referencia porcentual, dado que tiene un mayor volumen de sedimento excavado, puede apreciarse que sin ninguna duda el nivel más rico es PN 1, mientras que el Escalón III tiene una proporción comparativamente menor de la que le correspondería. PN 2, 3 y 4 revelan unos porcentajes similares a los del Escalón II. Por su parte, la relación que puede establecerse entre el número de fragmentos y el peso total del material de cada nivel muestra una uniformidad general salvo en PN 1 y PN 4, con índice de fragmentación algo más alto. Los porcentajes de piezas decoradas son muy bajos en general, superando apenas el 10\% en el mejor de los casos (Tab. 5). En esta escasísima población domina la pintura, aunque en PN 1 y PN 2 las líneas bruñidas son muy relevantes. Los cuatro primeros niveles presentan fragmentos decorados a peine, que faltan en los dos últimos. Las características por niveles son las siguientes:

Escalón II. La cerámica a torno supone algo más del $70 \%$ del total, aunque un $20 \%$ ha sido modelada a torno lento. Solo un $10 \%$ presenta decoración, en general pintada a base de bandas horizontales y paralelas de distinta anchura, destacando un motivo de círculos concéntricos (Fig. 7: 5). La mayoría son de pequeño tamaño, correspondientes a cuencos de borde apuntado redondeado algo entrante, alguno con perforaciones en el borde (Fig. 7: 3) y platos de labio exvasado, perfil ligeramente estrangulado y decoración de bandas horizontales y paralelas bícromas (Fig. 7: 4). También aparecen recipientes de tamaño medio tipo olla, con bordes exvasados excepto alguno de borde entrante (Fig. 7: 2) y vasos de almacenaje de gran tamaño (Fig. 7: 1). Los paralelos formales se integrarían en el repertorio documentado en el Guadiana y el Tajo Medio (Rodríguez Díaz y Ortiz Romero 2004). Hay pocas piezas de cerámica gris como un cuenco de borde engrosado al interior (Lorrio 1988-89: 284). En la cerámica a mano hay cuencos y recipientes de mediano tamaño con bordes de tendencia exvasada, así como bordes de posibles fuentes y galbos de grandes recipientes de almacenaje decorados con motivos estampillados simples (Fig. 7: 6). Estos tipos ya habían sido documentados en otros sectores del yacimiento (Ortega y Valle 2004: 181) y se citan como paralelos las procedentes del relativamente cercano castro vetton 


\begin{tabular}{|c|c|c|c|c|c|}
\hline $\begin{array}{c}\text { Ref. } \\
\text { Laboratorio }\end{array}$ & $\begin{array}{c}\mathrm{N}^{\mathbf{0}} \\
\text { Muestra /cm }\end{array}$ & Material & Fecha BP non cal & Fecha cal BC & $\begin{array}{c}\text { Punto mayor } \\
\text { probabilidad cal } \mathrm{BC}\end{array}$ \\
\hline Beta-324224 & $1 / 100$ & Metacarpo ciervo & $2250 \pm 30$ & $\begin{array}{l}392-348(33.5 \%) \\
317-207(66.5 \%)\end{array}$ & 283 \\
\hline Beta-308755 & $2 / 120$ & Carbón & $2440 \pm 30$ & $\begin{array}{l}751-686(23.3 \%) \\
667-637(8.0 \%) \\
622-614(1.0 \%) \\
595-406(67.7 \%)\end{array}$ & 531 \\
\hline CNA-697 & $3 / 130$ & Carbón & $2560 \pm 40$ & $\begin{array}{l}809-729(50.1 \%) \\
692-659(15.7 \%) \\
652-543(34.2 \%)\end{array}$ & 700 \\
\hline Beta-308756 & $4 / 140$ & Carbón & $2430 \pm 30$ & $\begin{array}{l}749-687(19.9 \%) \\
666-642(5.6 \%) \\
592-576(2.0 \%) \\
571-404(72.5 \%)\end{array}$ & 510 \\
\hline Beta-308757 & $5 / 170$ & Carbón & $2440 \pm 30$ & $\begin{array}{l}751-686(23.3 \%) \\
667-637(8.0 \%) \\
622-614(1.0 \%) \\
595-406(67.7 \%)\end{array}$ & 531 \\
\hline CNA-698 & $6 / 170$ & Carbón & $2555 \pm 30$ & $\begin{array}{l}802-746(56.5 \%) \\
688-664(16.7 \%) \\
645-551(26.8 \%)\end{array}$ & 759 \\
\hline CNA-699 & $7 / 210$ & Carbón & $2475 \pm 40$ & $\begin{array}{l}767-482(90.2 \%) \\
467-415(9.8 \%)\end{array}$ & 614 \\
\hline Beta-324225 & $8 / 220$ & Falange ciervo & $2470 \pm 30$ & $\begin{array}{l}762-681(30.1 \%) \\
672-484(61.2 \%) \\
465-416(8.7 \%)\end{array}$ & 616 \\
\hline Beta-308758 & $9 / 240$ & Carbón & $2460 \pm 30$ & $\begin{array}{l}756-684(27.9 \%) \\
669-606(18.6 \%) \\
603-478(39.1 \%) \\
472-414(14.4 \%)\end{array}$ & 593 \\
\hline
\end{tabular}

Tab. 2. Relación de fechas radiocarbónicas obtenidas en los distintos niveles de la fosa del Cerro de la Mesa (Alcolea de Tajo, Toledo). Muestras 1 y $2=$ Escalón III; 3 y $4=$ Perfil Norte 1; 5, 6 y 7 = Perfil Norte 2; 8 = Perfil Norte 3; $9=$ Perfil Norte 4 .

\begin{tabular}{|c|c|c|c|c|c|c|c|c|c|c|}
\hline \multirow{2}{*}{ Niveles } & \multirow{2}{*}{$\begin{array}{c}\text { Fgtos } \\
\mathrm{N}^{\mathrm{o}}\end{array}$} & \multicolumn{2}{|c|}{ Torno Ox } & \multicolumn{2}{|c|}{ Torno Red } & \multicolumn{2}{|c|}{ Mano Ox } & \multicolumn{2}{|c|}{ Mano Red } & \multirow{2}{*}{$\begin{array}{c}\text { Peso } \\
\text { (gr) }\end{array}$} \\
\hline & & $\mathrm{N}^{\mathrm{o}}$ & $\%$ & $\mathrm{~N}^{\mathrm{o}}$ & $\%$ & $\mathrm{~N}^{\mathrm{o}}$ & $\%$ & $\mathrm{~N}^{\mathrm{o}}$ & $\%$ & \\
\hline Escalón II, 604, 606 & 1320 & 545 & 41,29 & 402 & 30,45 & 125 & 9,47 & 248 & 18,79 & 19138 \\
\hline Escalón III, 604, 606 & 936 & 361 & 38,57 & 386 & 41,24 & 57 & 6,09 & 132 & 14,10 & 13163 \\
\hline Perfil Norte 1 & 761 & 84 & 11,04 & 171 & 22,47 & 139 & 18,27 & 367 & 48,22 & 14329,5 \\
\hline Perfil Norte 2 & 397 & 126 & 31,74 & 102 & 25,69 & 29 & 7,30 & 140 & 35,26 & 5431,5 \\
\hline Perfil Norte 3 & 248 & 83 & 33,47 & 53 & 21,37 & 30 & 12,10 & 82 & 33,06 & 3502,5 \\
\hline Perfil Norte 4 & 195 & 70 & 35,90 & 41 & 21,10 & 13 & 6,67 & 71 & 36,41 & 3718,5 \\
\hline
\end{tabular}

Tab. 3. Número de fragmentos cerámicos, manufactura y cocción (ox oxidante; red reductora) y peso del conjunto por niveles del Cerro de la Mesa (Alcolea de Tajo, Toledo). 


\begin{tabular}{|l|c|c|c|c|}
\hline \multicolumn{1}{|c|}{ Niveles } & \% Vol. Exc. & \% N $\mathbf{N}^{\mathbf{~ F r g} .}$ & \% Peso & Peso/No Fgr. \\
\hline Escalón II + 604 +606 & 100 & 100 & 100 & 14 \\
\hline Escalón III + 604 +606 & 92 & 71 & 69 & 14 \\
\hline Perfil Norte 1 & 25 & 58 & 75 & 19 \\
\hline Perfil Norte 2 & 27 & 30 & 28 & 14 \\
\hline Perfil Norte 3 & 18 & 19 & 18 & 14 \\
\hline Perfil Norte 4 & 20 & 15 & 19 & 19 \\
\hline
\end{tabular}

Tab. 4. Cerro de Mesa, porcentajes de volumen de tierra excavada, número y peso de fragmentos en relación al máximo representado por Escalón II+604+606. Relación entre el peso y el número de fragmentos por niveles.

\begin{tabular}{|c|c|c|c|c|c|c|c|c|c|c|c|c|c|c|c|}
\hline Niveles & $\begin{array}{l}\text { Piezas } \\
\text { decor. }\end{array}$ & Pint. & $\%$ & $\begin{array}{l}\text { Est./ } \\
\text { Imp. }\end{array}$ & $\%$ & Peine & $\%$ & $\begin{array}{l}\text { Lín. } \\
\text { Bruñ. }\end{array}$ & $\%$ & Incis. & $\%$ & $\begin{array}{l}\text { Dig./ } \\
\text { Ung. }\end{array}$ & $\%$ & Otros & $\%$ \\
\hline Escalón II & 134 & 111 & 82,84 & 10 & 7,46 & 3 & 2,24 & 0 & 0,00 & 7 & 5,22 & 3 & 2,24 & 0 & 0,00 \\
\hline Escalón III & 99 & 77 & 77,78 & 4 & 4,04 & 4 & 4,04 & 6 & 6,06 & 3 & 3,03 & 2 & 2,02 & 3 & 3,03 \\
\hline Perfil Norte 1 & 30 & 6 & 20,00 & 0 & 0,00 & 4 & 13,33 & 11 & 36,67 & 6 & 20,00 & 2 & 6,67 & 1 & 3,33 \\
\hline Perfil Norte 2 & 33 & 12 & 36,36 & 2 & 6,06 & 2 & 6,06 & 11 & 33,33 & 4 & 12,12 & 1 & 3,03 & 1 & 3,03 \\
\hline Perfil Norte 3 & 18 & 10 & 55,56 & 0 & 0,00 & 0 & 0,00 & 4 & 22,22 & 4 & 22,22 & 0 & 0,00 & 0 & 0,00 \\
\hline Perfil Norte 4 & 21 & 17 & 80,95 & 0 & 0,00 & 0 & 0,00 & 3 & 14,29 & 1 & 4,76 & 0 & 0,00 & 0 & 0,00 \\
\hline
\end{tabular}

Tab 5. Cantidad y porcentaje de piezas decoradas por niveles del Cerro de la Mesa. Pint = Pintada; Est/Imp. = Estampilla/Impresión; Lín. Bruñ. = Líneas bruñidas; Dig/Ung = Digitación/Ungulación.

del Raso de Candeleda (Fernández Gómez 1986, 2011: 346, 349, 351).

Escalón III. El porcentaje de la cerámica a torno aumenta a casi el $80 \%$ del total, y más del $30 \%$ corresponde a torno lento. Los fragmentos decorados son solo el $7 \%$ de la producción siendo mayoritarias las bandas horizontales pintadas de distinta anchura, a veces completadas con grupos de trazos horizontales y paralelos (Fig. 7: 7). Hay un solo caso de barniz rojo, alguna decoración bícroma en rojo y negro, así como líneas bruñidas que siguen la orientación del torno confiriendo a la superficie un efecto similar a la decoración de bandas horizontales. Entre los vasos de pequeño tamaño destacan los cuencos de borde redondeado y platos de perfil ligeramente carenado (Fig. 7: 3), algunos decorados con bandas horizontales y paralelas de color rojizo. Destaca una pieza (Fig. 7: 6) cuyo perfil carenado tiene paralelos en la necrópolis de Las Cogotas (Cabré 1932: Lám. LIX). En cerámica gris se documentan cuencos de borde simple redondeado o ligeramente engrosado, con alguno de tamaño medio con perforaciones postcocción en la zona del borde (Fig. 7: 2 y 5), así como un recipiente de gran tamaño de borde inclinado y labio plano de tipología imprecisa (Fig. 7: 8). Los cuencos son muy similares a los documentados en la próxima zona de "altar" asociados a un conjunto de ánforas, fechado inicialmente en el siglo VI a.C. (Ortega y Valle 2004: 178-179) se podría rebajar su cronología a fines del siglo VI y principios del V a.C. Sus paralelos se sitúan en Medellín y La Mata de Campanario (Rodríguez Díaz y Ortiz Romero 2004: 252; Lorrio 2008: 675). En la cerámica a mano destacan las ollas de tamaño medio, borde exvasado, cuello poco desarrollado y cuerpo globular (Fig. 7: 1), elementos de suspensión como asas de sección plana (Fig. 7: 4) y orzas o vasos de almacenaje de gran tamaño.

PN 1. En este estrato se invierte la relación de los porcentajes de cerámica, descendiendo la producción a torno a poco más de un 30\%. Los escasos fragmentos decorados mantienen las bandas, en algún caso con bicromía en rojo y negro. Las formas principales son las ollas de borde exvasa- 
do, cuello corto y perfil globular (Fig. 7: 1) ampliamente documentadas en el Tajo Medio (Fernández Gómez 1986; Rodríguez y Pavón 1999; Rodríguez Díaz y Ortiz Romero: 2004; 235, 244). También son característicos los cuencos de borde ligeramente engrosado, decorados en el borde con bandas bícromas (Fig. 7: 6). Su cronología en el valle del Guadalquivir, Huelva y las cuencas medias del Guadiana y del Tajo (Rodríguez Díaz y Ortiz Romero 2004: 249) es de finales del siglo V a.C. En la cerámica gris, destacan los cuencos de mediano y pequeño tamaño de gran calidad en las pastas y acabados superficiales (Fig. 7: 5 y 7), con paralelos cercanos en el Guadiana Medio fechados entre el siglo VI y el IV a.C. (Lorrio, 2008: 678; Hernández Carretero 1993: 59; Rodríguez Díaz y Ortiz Romero 2004: 255). En la cerámica a mano aparecen pequeños fragmentos con decoración a peine junto con decoraciones plásticas a base de digitaciones. En estas producciones se advierte una mayor variedad tipológica con recipientes de tamaño medio, borde exvasado, cuello corto y perfil globular o de tendencia ovoide (Fig. 7: 1 y 4) junto con otros de tamaño medio y perfiles ligeramente acampanados, que presentan decoraciones de tipo plástico en el sector exterior del borde (Fig. 7: 3). Cabe reseñar una fusayola de perfil troncocónico (Fig. 7: 8).

PN 2. Este estrato documenta una mayor igualdad entre los porcentajes de cerámica a torno (dominante) y a mano. La primera se caracteriza por galbos de recipientes de gran tamaño (Fig. 8: 4) y bordes exvasados, redondeados y ligeramente engrosados pertenecientes a platos de tamaño medio, con decoración pintada localizada en el borde (Fig. 8: 1-3). Se mantiene la variedad de sistemas decorativos, destacando los motivos geométricos y bandas paralelas pintadas, junto con las líneas bruñidas. En la cerámica a mano también se han documentado cuencos de borde redondeado, junto con bordes exvasados, fondos de orzas de tamaño medio y galbos de recipientes de almacenaje de gran tamaño. Cabe destacar un recipiente de borde exvasado y tamaño medio decorado mediante ungulaciones y digitaciones localizadas en el borde y el cordón (Fig. 8: 8). Las incisiones a peine aparecen en un formato de mayor tamaño que en el estrato anterior (Fig. 8: 5-7) y permiten identificar y comparar los motivos con los procedentes en la fase de plenitud de otros lugares clásicos del territorio vettón, como Las Cogotas o La Osera (Ruiz Zapatero y Álvarez-Sanchís 2002: 265), o el más próximo de El Raso (Fernández Gómez 1986: 268). Este tipo de decoración, considerada como uno de los elementos del registro arqueológico que se identifica con el desarrollo y expansión de las comunidades vettonas (Ruiz Zapatero y Alvarez Sanchís 2002: 266), fue documentada en otros sectores del Cerro de la Mesa con una cronología del siglo IV a.C. (Ortega y Valle 2004: 181).

PN 3. La cerámica a torno supone aquí un 55\% y consiste mayoritariamente en cuencos con el borde engrosado y vuelto ligeramente al interior y cazuelas de tamaño medio y grande de borde exvasado y ligero estrangulamiento (Fig. 8: 4 y 7). Las piezas decoradas no llegan al 7\% del total, limitándose a bandas horizontales de color rojizo o marrón y a líneas bruñidas. La cerámica gris, de cuidada factura, muestra bordes de cuencos ligeramente engrosados y tendencia recta, así como fondos planos de recipientes de tamaño medio (Fig. 8: 2-3). A mano hay ollas de borde exvasado de tamaños medio y grande (Fig. 8: 1) $\mathrm{y}$ cuencos de borde apuntado y ligero perfil en $\mathrm{S}$. Se documentan motivos incisos probablemente a peine (Fig. 8: 5-6). Sin excluir que haya materiales a torno de una fecha posterior, los cuencos de borde engrosado y las cerámicas grises proporcionan para este conjunto cerámico, a tenor de los paralelos antes citados, una cronología en torno al siglo $\mathrm{V}$ a.C., con posible perduración en el IV a.C. para las cerámicas a peine.

PN 4. La cerámica a torno representa el 57\%, destacando los bordes y galbos de recipientes de gran tamaño, con pastas, acabados y decoraciones (Fig. 8: 7-9) semejantes a los ejemplares documentados en el sector del "lingote chipriota" (Ortega y Valle 2004: Lám. III). Las piezas son evolución de formas anfóricas de cronología más antigua, como las derivadas del pithos, que se pueden integrar sin dificultades en las producciones del siglo VI-V a.C. del Suroeste peninsular (Ramón Torres 1995: 78-94; Rodero 1995; Belén Deamos 2006: 240). Se documentan también cuencos de borde ligeramente engrosado y vuelto al interior, junto con ollas de bordes de tendencia recta y ligeramente estrangulados (Fig. 8: 2 y 4). En la cerámica a mano destacan los cuencos de borde redondeado ligeramente vuelto al interior, ollas de cuerpo de tendencia esférica y cuello ligeramente exvasado (Fig. 8: 3), así como piezas de pasta

Trab. Prehist., 70, N. ${ }^{\circ}$ 1, enero-junio 2013, pp 140-165, ISSN: 0082-5638

doi: $10.3989 /$ tp.2013.12106 


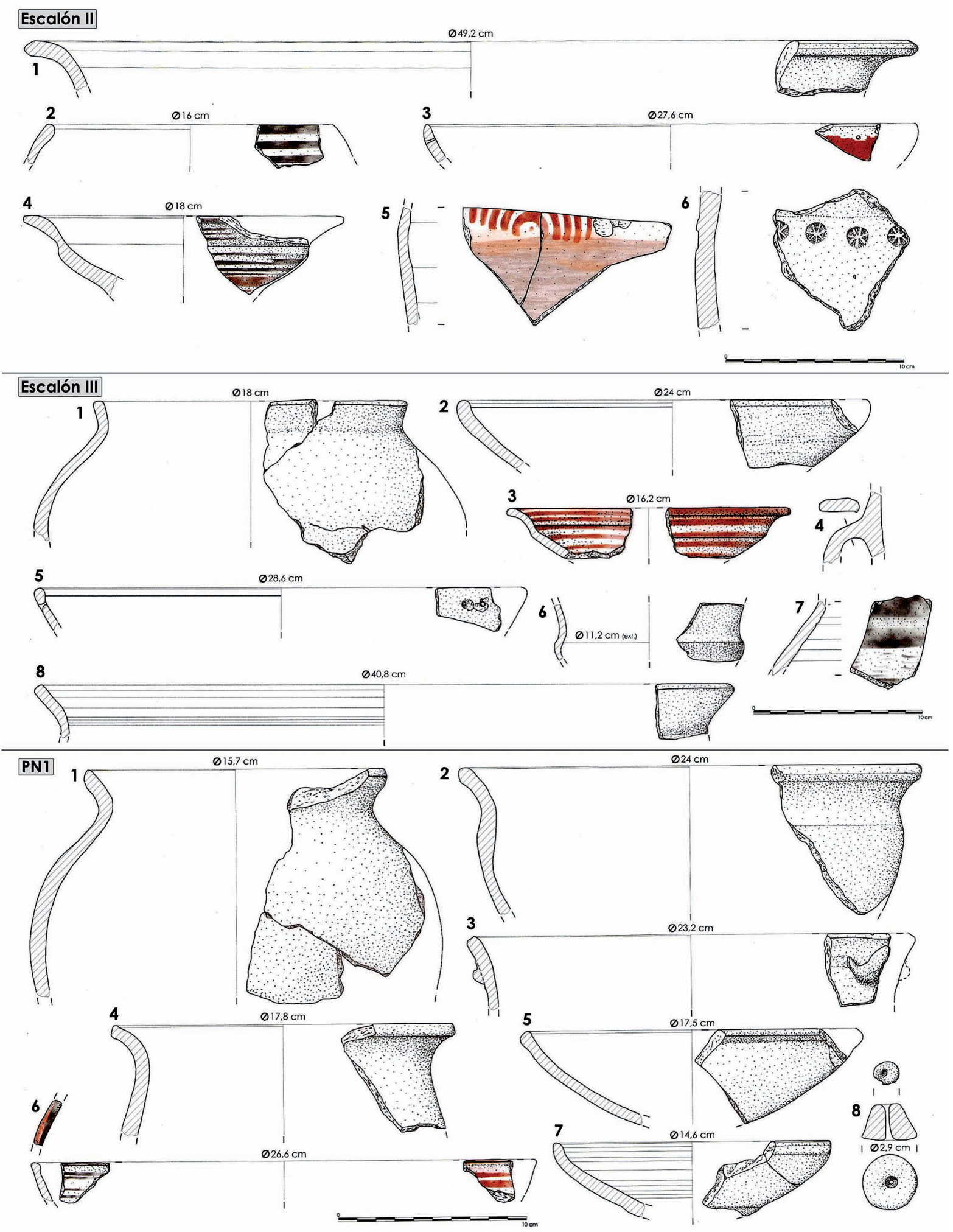

Fig. 7. Muestra cerámica de los niveles superiores de la fosa-vertedero.

Trab. Prehist., 70, N. ${ }^{\circ}$ 1, enero-junio 2013, pp 140-165, ISSN: 0082-5638 doi: $10.3989 /$ tp.2013.12106 
PN2
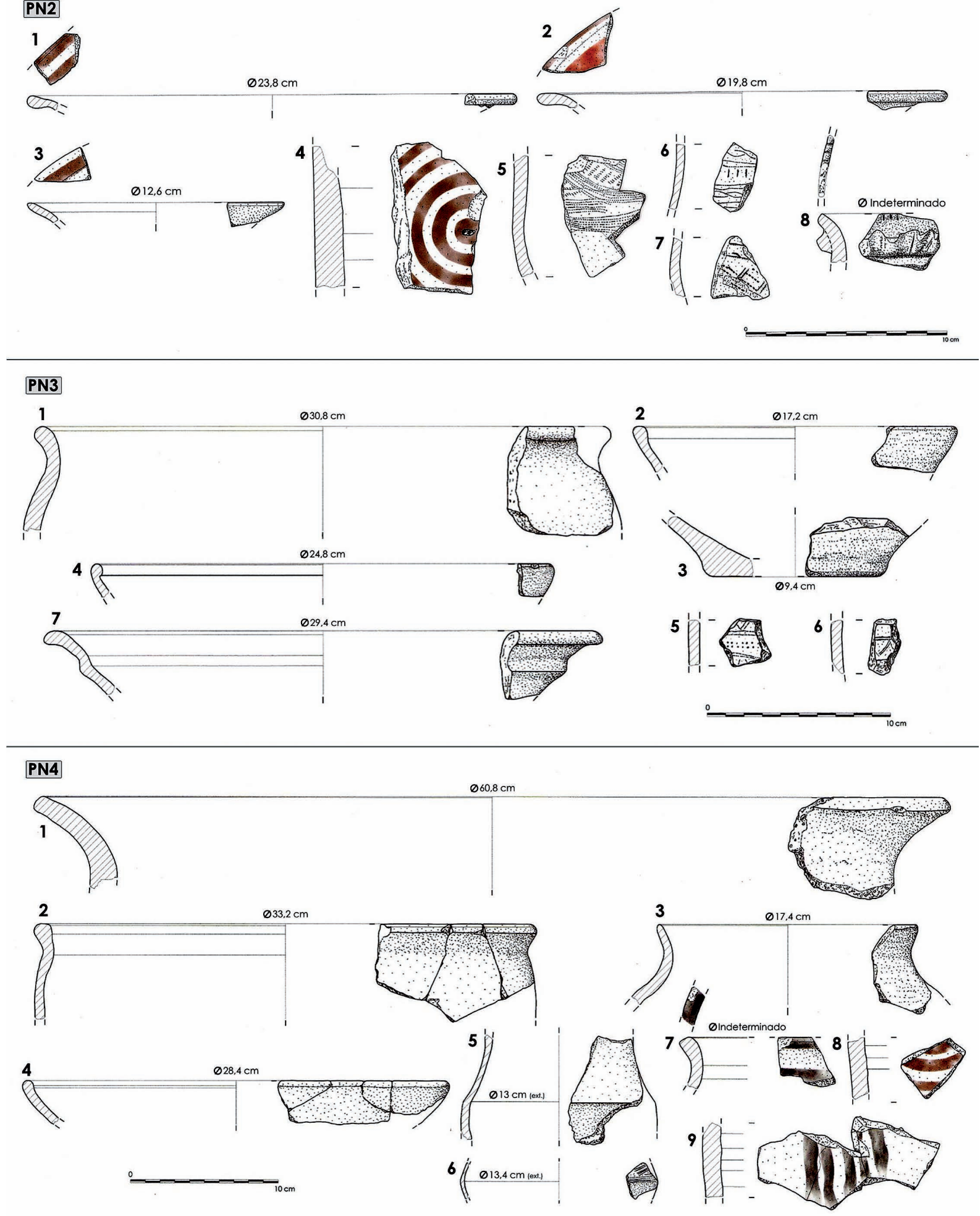

Fig. 8. Muestra cerámica de los niveles inferiores de la fosa-vertedero del Cerro de la Mesa (Alcolea de Tajo, Toledo).

Trab. Prehist., 70, N. ${ }^{\circ}$ 1, enero-junio 2013, pp 140-165, ISSN: 0082-5638 doi: $10.3989 /$ tp.2013.12106 
más cuidada en factura y acabados superficiales, con perfiles carenados, una con decoración incisa de tipo geométrico (Fig. 8: 5-6). Por último hay fragmentos de grandes recipientes de borde exvasado y cuello acampanado (Fig. 8: 1). Uno se asocia a los anforoides del contexto del "lingote chipriota". Su cronología de finales del siglo VI a.C. evidencia la pervivencia de estos recipientes, presentes en contextos funerarios del valle medio del Tajo desde principios del siglo VII a.C. (Pereira 2008: 198).

Tomamos Escalón II como referencia para analizar el comportamiento del resto de los niveles, siendo el porcentaje de material a torno respecto al de mano de 72/28. Escalón III presenta menos materiales respecto al volumen de tierra extraído. Su fragmentación es similar a otros y el volumen de torno es el más alto del conjunto. PN 1 tiene el conjunto más numeroso de materiales y el mayor índice de fragmentación. El porcentaje de piezas a mano es el más alto. PN 2 y PN 3 tienen un comportamiento muy similar entre sí, correspondiéndose con los datos del Escalón II respecto al número de fragmentos recuperados en relación a la zona excavada y a su grado de fragmentación. Muestran más piezas a mano que los Escalones II y III, si bien estas no llegan a superar a las hechas a torno. PN 4 se comporta como los anteriores en todo excepto en que su grado de fragmentación, es similar al de PN 1.

\section{OTROS MATERIALES}

Cabe destacar dos piezas tubulares sobre hueso de ovicáprido decoradas en los extremos a base de una retícula romboidal incisa. La más completa $(8,9 \mathrm{~cm})$ procede del nivel PN 2 (Fig. 9: 3). La decoración está muy desvaída debido a un uso continuo que se infiere del aspecto pulido de su superficie. La segunda se halló en el nivel PN 3 y conserva solo un extremo $(7,4 \mathrm{~cm})$ con un motivo decorativo en mejor estado (Fig. 9:2). Durante la limpieza del interior el análisis de los restos detectó la presencia de partículas microscópicas de oro (2). Estas piezas tienen su mejor

(2) La identificación fue realizada por Alicia Perea y Oscar García Vuelta en el Laboratorio de Microscopía Electrónica y Microanálisis MicroLab del CCHS, CSIC, Madrid. paralelo en las tumbas 9 y 104 de la zona VI de la necrópolis de La Osera con una cronología entre el siglo V y el III a.C. (Cabré et al. 1950: 82 fig. 9; 98 fig. 10).

A estos materiales puede unirse una cabecita zoomorfa de barro gris procedente de PN 3. (Fig. 9:1). Con unos $4 \mathrm{~cm}$ de altura, representa el morro y el arranque del cuello de un posible équido. Los ojos y la boca están marcados con unas incisiones, y la parte correspondiente a las orejas se apunta con una protuberancia que está fragmentada. Una figurita similar se ha localizado en una zona de basurero fechada en el siglo III a.C. en el yacimiento de las Cogotas (Alonso y Benito 199192: 366). Estas representaciones zoomorfas de pequeños prótomos de terracota son conocidas en la iconografía de otros pueblos peninsulares (Blanco 2003: 87; Alfayé 2010: 554-55).

Los elementos metálicos conservados no son muy abundantes: dos pequeños punzones de bronce de sección cuadrangular (Fig. 9: 4), una laminita de bronce y un vástago torsionado a modo de gancho con dos pequeños apéndices en uno de sus extremos. Todos proceden del nivel PN 1.

\section{PALEOVEGETACIÓN}

En el perfil estratigráfico $(250 \mathrm{~cm})$ de la fosa se tomaron 25 muestras para análisis polínico a intervalos regulares de $10 \mathrm{~cm}$. El tratamiento químico fue el usual en los estudios arqueopalinológicos (Burjachs et al. 2003), siguiendo las directrices estadísticas y tafonómicas expuestas en López Sáez et al. (2003; López Sáez et al. 2006). Las muestras resultaron fértiles, exceptuando las situadas en el intervalo 110-180 cm (base del Escalón III, PN 1, techo PN 2) y una más a $200 \mathrm{~cm}$ (base PN 2), cuyo alto contenido en cenizas impidió la conservación del contingente esporo-polínico por altas temperaturas (López Sáez et al. 2003). Los palinomorfos, polínicos y no polínicos, fueron identificados en un microscopio óptico $(60 \mathrm{x}, 40 \mathrm{x})$, siguiendo la nomenclatura tipológica de Moore et al. (1991) y López Sáez et al. (1998; López Sáez et al. 2000), y mediante la comparación con la palinoteca del Laboratorio de Arqueobiología (CCHS, CSIC). En la tabla 6 se muestra el histograma palinológico derivado de este estudio, incluyéndose las del Es- 


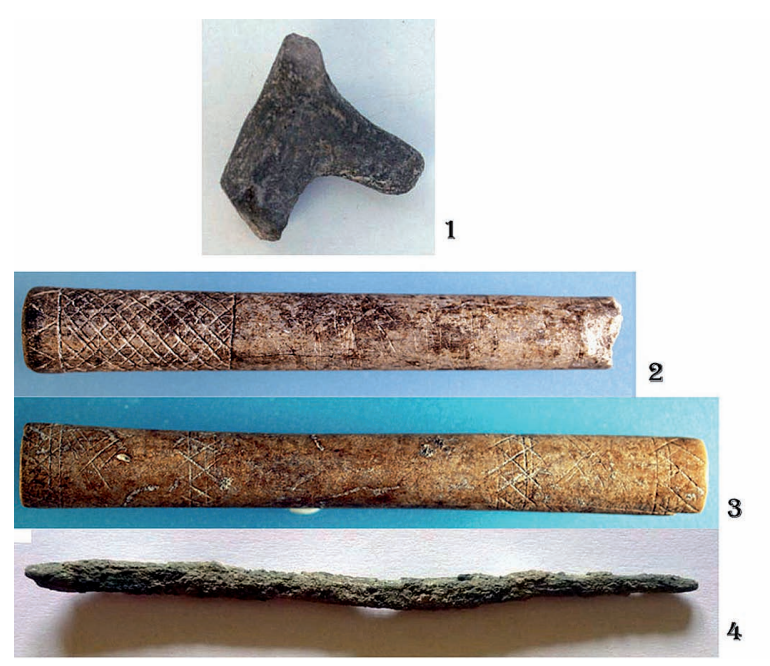

Fig. 9. 1. Cabecita zoomorfa de barro; 2-3. Mangos decorados de hueso; 4. Punzón de bronce.

calón 1 para completar la información, a pesar de que, por las razones antes citadas, no se ha tenido en cuenta este nivel en el estudio de los materiales arqueológicos.

Las muestras del análisis antracológico corresponden al Escalón II (Tab. 7) y fueron recogidas a mano durante los procesos de excavación y flotación. Se han identificado todos los fragmentos $>2 \mathrm{~mm}$, empleando un microscopio de luz incidente $(50 \mathrm{x}, 100 \mathrm{x}, 200 \mathrm{x}, 500 \mathrm{x})$ y reconociendo sus secciones transversal, longitudinal radial y tangencial. Para ello se ha establecido un marco comparativo de las características del material arqueológico estudiado con la colección de referencia (antracoteca) del Laboratorio de Arqueobiología (CCHS, CSIC), consultando también los atlas de anatomía de maderas de Schweingruber $(1978,1990)$ y Vernet et al. (2001).

\subsection{Serie inferior $(250-190 \mathrm{~cm})$}

En la base de PN 2, PN 3 y PN 4, el porcentaje de polen arbóreo (Tab. 6) decrece progresivamente desde el $54 \%$ de la muestra más profunda al $28-34 \%$ de las más superficiales. En cualquier caso, el paisaje que se infiere de los espectros polínicos de estas muestras es un en- cinar muy aclarado, donde la encina (Quercus perennifolio) apenas representa el 4-8\%. Otros elementos arbóreos serían el alcornoque (Quercus suber, 0-3\%), cuyos bajos porcentajes sugieren una presencia muy puntual en el entorno inmediato del yacimiento, fundamentalmente en aquellos suelos más profundos, y el pino resinero (Pinus pinaster, 1-5\%), cuya naturalidad en estas cronologías ha sido demostrada en el piedemonte de la vertiente meridional de la Sierra de Gredos (López Sáez et al. 2010b). Algunos palinomorfos arbustivos (11-22\%) documentados son el acebuche (Olea europaea, 1-4\%) y el labiérnago (Phillyrea, 0-2\%). Ambos son elementos típicos de la facies termófila del encinar luso-extremadurense, que sería la vegetación climática del área de estudio; mientras que las jaras (Cistus, 3-7\%) y los brezos (Erica, 4-7\%) representarían etapas de degradación de la cobertura forestal debido a la acción antrópica.

El palinomorfo arbóreo mayoritario es Pinus sylvestris (18-43\%), cuyo alto porcentaje no implica necesariamente su presencia local, sino su sobrerrepresentación en los espectros polínicos gracias a la gran capacidad dispersiva de su polen y la baja cobertura arbórea del encinar que permitiría su llegada a estos sedimentos. Estudios de lluvia polínica actual, en el ámbito de la Sierra de Gredos, de donde procederían estos pólenes de pinos altimontanos (Pinus sylvestris o P. nigra), han demostrado que porcentajes de este palinomorfo por debajo del 50\% denotan el carácter regional, que no local, de su procedencia (Andrade et al. 1994).

La flora herbácea domina porcentualmente en esta fase (34-55\%), siendo el palinomorfo mayoritario Poaceae (13-22\%), reflejando la existencia de amplios pastizales de gramíneas en las zonas aclaradas del encinar. Junto a estas, abundan toda una serie de palinomorfos de carácter antrópico y nitrófilo (Aster, Cardueae, Centaurea nigra, Cichorioideae, Convolvulus arvensis, Dipsacus fullonum), fruto de la elevada antropización del entorno inmediato del yacimiento (Behre 1981; López Sáez et al. 2003). La identificación de algunos elementos pirófilos, como las citadas jaras y los brezos, así como de Asphodelus albus (0$2 \%$ ), e incluso de ascosporas fúngicas de especies carbonícolas (Chaetomium, 0-3\%), apunta al uso del fuego como elemento de aclarado del bosque (López Sáez et al. 1998). 


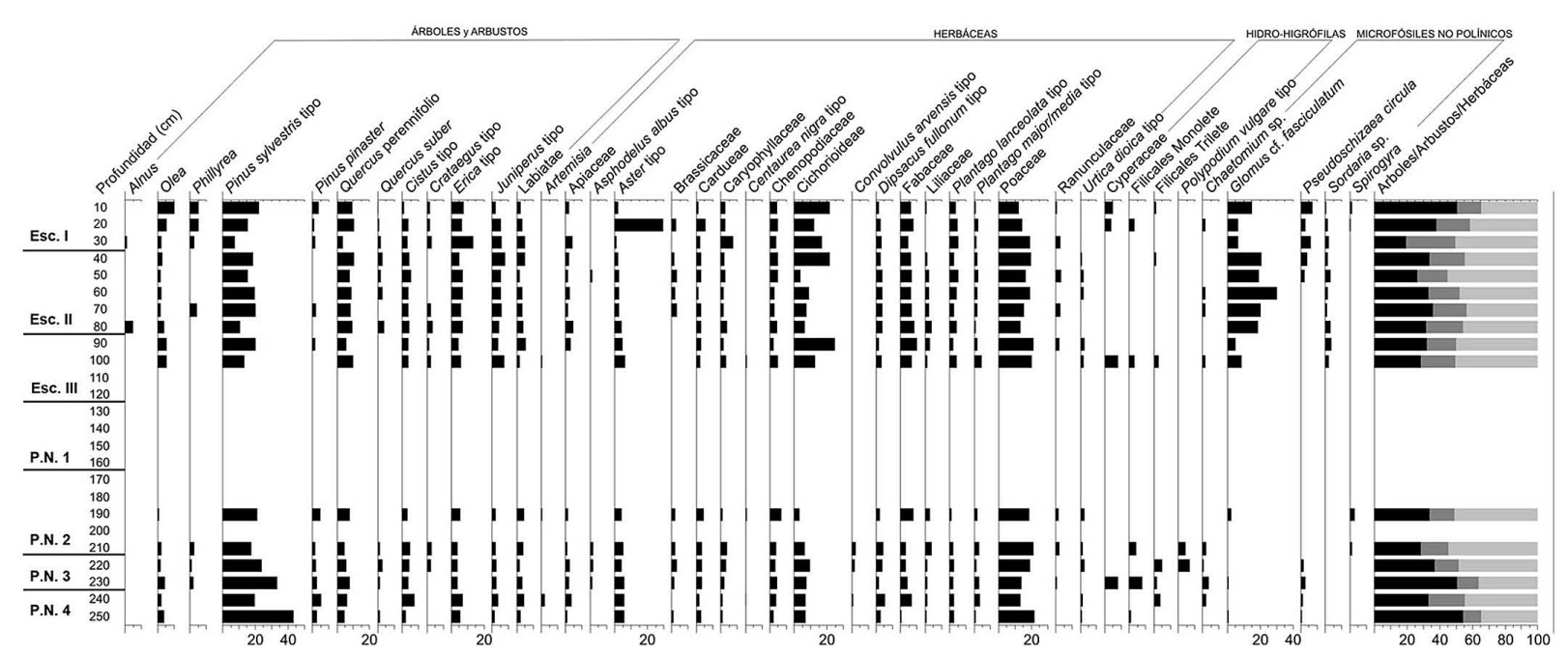

Tab. 6. Diagrama polínico de los niveles de la fosa. Esc. = Escalón; PN = Perfil Norte.

\begin{tabular}{|c|c|c|c|c|c|c|c|c|}
\hline \multirow{2}{*}{ ESCALÓN II } & \multicolumn{2}{|c|}{ Muestra 1} & \multicolumn{2}{|c|}{ Muestra 2} & \multicolumn{2}{|c|}{ Muestra 3} & \multicolumn{2}{|c|}{ Muestra 4} \\
\hline & $\mathbf{N}^{\mathbf{0}}$ & $\%$ & $\mathbf{N}^{\mathbf{0}}$ & $\%$ & $\mathbf{N}^{\mathbf{0}}$ & $\%$ & $\mathbf{N}^{\mathbf{0}}$ & $\%$ \\
\hline Erica sp. & 2 & 1,5 & 17 & 15,9 & 13 & 24,5 & 4 & 19 \\
\hline Olea europaea & & & 1 & 0,9 & & & 1 & 4,8 \\
\hline Pinus sp. & 20 & 14,7 & 21 & 19,6 & 11 & 20,8 & 2 & 9,5 \\
\hline Prunus sp. & 1 & 0,7 & 11 & 10,3 & 2 & 3,8 & 1 & 4,8 \\
\hline Quercus ilex/coccifera & 1 & 0,7 & 30 & 28 & 4 & 7,5 & 4 & 19 \\
\hline Quercus subg. Quercus & 39 & 28,7 & 27 & 25,2 & 23 & 43,4 & 9 & 42,9 \\
\hline Quercus sp. & 73 & 53,7 & & & & & & \\
\hline TOTAL & 136 & & 107 & & 53 & & 21 & \\
\hline Corcho & & & & & & 6 & & \\
\hline No identificable & 16 & & 3 & & 8 & & 9 & \\
\hline
\end{tabular}

Tab. 7. Valores absolutos y porcentuales del análisis antracológico del Cerro de la Mesa ( $\mathrm{n}=340)$ correspondientes al Escalón II.

No se ha identificado polen de cereales, lo que no excluye necesariamente las actividades agrícolas. Las particulares características del polen de Cerealia, con escasa capacidad dispersiva, tanto por su gran tamaño como por la baja producción debido a su carácter autopolinizante, provocan que solo si los campos de cultivo están a menos de 100-200 m pueda documentarse este palinomorfo en los estudios arqueopalinológicos (López Sáez y López Merino 2005). En cambio, la relativa abundancia de palinomorfos antropozoógenos (Chenopodiaceae, Plantago lanceolada, Plantago major/media, Urtica dioica) permite suponer cierto tipo de presión pastoral en las cercanías del sitio (López Sáez y López Merino 2007). 


\subsection{Serie superior $(100-10 \mathrm{~cm})$}

A diferencia de la anterior, en esta serie (Escalones I y II, techo del Escalón III) la cobertura arbórea va incrementándose progresivamente, desde el $28 \%$ en la muestra basal al $51 \%$ de la del techo. Estos hechos se deben a la recuperación del encinar (Quercus perennifolio, $\sim 11 \%$ ) y de su cobertura arbustiva de acebuches (Olea, $2-10 \%)$ y labiérnagos (Phillyrea, 0-6\%); mientras que elementos seriales degradativos como las jaras y los brezos se mantienen en porcentajes semejantes a la fase anterior. El análisis antracológico demuestra la presencia local de brezos (Erica) -con valores porcentuales importantes $(19-24,5 \%)$ en algunas muestras del Escalón 2- y acebuches (0,9-4,8\%). Alcornoque y pino resinero se mantienen en el diagrama palinológico. En el estudio antracológico correspondiente al Escalón II (Tab. 7) se han identificado restos de Quercus subg. Quercus e incluso 6 restos carbonizados muy bien conservados de corcho), todo lo cual permitiría admitir el carácter local del alcornoque (Quercus suber) en el área de estudio.

La razón de esta recuperación progresiva de la cobertura forestal de encinar sería una presión antrópica menos intensa, toda vez que la incidencia del fuego parece no ser recurrente (Asphodelus albus y Chaetomium son esporádicas y con menores valores que en la fase precedente). La presión pastoral, no obstante, supera la de la fase anterior, puesto que los palinomorfos antropozoógenos descritos con anterioridad persisten en porcentajes más elevados, especialmente Plantago lanceolata (2-5\%). Incluso en esta serie superior podría suponerse que hay ganado in situ en el propio yacimiento, ya que se documentan ascosporas fúngicas de especies coprófilas del género Sordaria (0,5-3\%) (López Sáez y López Merino 2007). Cabría pensar, de acuerdo a ello, en una explotación sostenible del encinar ante una presencia local de la cabaña ganadera, que permitiera su recuperación progresiva. Los datos antracológicos denotan una importancia porcentual de la encina (Quercus ilex/coccifera) semejante a la de brezos, pinos y quercíneas caducifolias para el Escalón II.

Hay pinos en todas las muestras antracológicas estudiadas, tanto en el Escalón II (9,5-20,8\%) como en el Escalón I (52,2\%), no habiendo sido posible su identificación a nivel específico. De acuerdo con el diagrama polínico y el elevado porcentaje que los restos de carbón ofrecen en el Escalón I, podría pensarse que tales restos procederían del pino resinero (Pinus pinaster), que como ya se dijo es una especie cuya naturalidad ha sido plenamente demostrada en el sur de la Sierra de Gredos (López Sáez et al. 2010b). De hecho, los valores porcentuales de este palinomorfo son inferiores a los de la serie inferior, e incluso en algunas muestras del Escalón II (40-50 y $80 \mathrm{~cm})$ ni siquiera se documentan, lo que podría corroborar su importancia porcentual en el estudio antracológico. Es posible, por tanto, que existieran algunos pinares de Pinus pinaster, probablemente en dominios aluviales arenosos, pues no en vano se ha documentado esta especie, tanto en el registro antracológico como palinológico, de la villa romana de El Saucedo, en esta misma comarca (Castelo Ruano et al. 2010-2011). También es posible que tales restos antracológicos de pino procedan de pinares altimontanos como el pino albar (Pinus sylvestris) o el laricio (Pinus nigra), representados en el diagrama palinológico por el morfotipo Pinus sylvestris con valores elevados superiores al $20 \%$. En este caso habría que pensar en desplazamientos de larga distancia para el aprovisionamiento de estas maderas, pues ambas especies de pino solo crecen en zonas relativamente elevadas, y poco accesibles, de la Sierra de Gredos al norte del Cerro de la Mesa.

Sin embargo, a pesar de lo comentado, es cierto que en esta serie superior los palinomorfos antrópicos y nitrófilos se hacen incluso más abundantes, siendo especialmente reseñable el caso de Cichorioideae ( $25 \%)$, o de Aster (30\%) en la muestra $20 \mathrm{~cm}$. Estos datos permitirían suponer una presión antrópica mucho mayor, con la consabida y esperada reducción de la cobertura forestal, pero no ha sido así. No obstante, para explicar estos hechos, ha de citarse que entre los microfósiles no polínicos se documentan dos indicadores de procesos erosivos, de muy diversa índole, como Pseudoschizaea circula y Glomus cf. fasciculatum (López Sáez et al. 2000), presentes conjuntamente en estos niveles superiores. Su identificación permitiría suponer que dichos procesos erosivos, en el depósito sedimentario de la fosa-vertedero, podrían tener algún tipo de relación con la construcción de las casas vettonas y la contaminación de las muestras de esta serie superior con sedimentos incorporados a posteriori, de ahí la diferencia-

Trab. Prehist., 70, N. ${ }^{\circ}$ 1, enero-junio 2013, pp 140-165, ISSN: 0082-5638

doi: $10.3989 /$ tp.2013.12106 
ción tan clara en dos fases descrita por el análisis palinológico. Esto es perfectamente asumible si se considera la fecha ${ }^{14} \mathrm{C}$ obtenida a los $100 \mathrm{~cm}$ del registro (ca. 390-205 cal BC), que nos lleva a cronologías de la Segunda Edad del Hierro y que es completamente asincrónica con las dataciones más profundas, siempre anteriores al $400 \mathrm{cal}$ BC.

Finalmente, a lo largo de esta serie superior, hay una disminución porcentual progresiva del pino (Pinus sylvestris) como taxón mayoritario, que ya comenzó a vislumbrarse a lo largo de la serie inferior. Diversos registros paleopalinológicos en turberas de la Sierra de Gredos han demostrado que un incremento sustancial de la pluviosidad, a lo largo del I milenio cal BC, produjo el declive de los pinares situados en zonas de alta montaña, dado su carácter más continental (Franco Múgica 2009). En el fondo del valle se reducirían sensiblemente los encinares a favor de los robledales, a la vez que decrecerían los porcentajes de elementos xerófilos y termófilos como Artemisia o el acebuche (Olea europaea) (López Sáez et al. 2010a). Estos hechos se advierten perfectamente en el registro polínico del Cerro de la Mesa, toda vez que (i) Artemisia desaparece a lo largo de esta serie superior, siendo su presencia muy esporádica en la anterior, (ii) se incrementan los valores de elementos propios de pastizales húmedos (Apiaceae, Cyperaceae, Ranunculaceae), (iii) se documenta por primera vez polen de aliso (Alnus), elemento arbóreo característico de los bosques galería de la región, y, (iv), la ya comentada disminución porcentual gradual de Pinus sylvestris. Que en el diagrama palinológico del Cerro de la Mesa no se advierta, en estos momentos, una reducción de los valores de acebuche, sino todo lo contrario, tiene más que ver con el hecho ya comentado de una gestión sostenible de la dehesa de encinas que con condiciones climáticas que le serían desfavorables.

Finalmente, en la serie superior tampoco se han identificado pólenes de cereales, pero sí valores relativamente elevados de leguminosas indiferenciadas (5-10\%). Aunque morfológicamente no sea posible la diferenciación específica de la mayoría de especies cultivadas de Fabaceae, porcentajes tan elevados, de un taxón de por sí zoófilo, podrían estar haciendo referencia a su cultivo (López Sáez et al. 2003).

En definitiva, el estudio palinológico y antracológico del Cerro de la Mesa demuestra la existencia, a lo largo del I milenio cal BC, de un paisaje de encinar sumamente aclarado en el entorno del yacimiento, con algunos alcornoques dispersos en suelos más profundos, pinares de pino resinero hacia los valles meridionales de la Sierra de Gredos, y bosques de pino albar y/o laricio a cotas más elevadas. La flora herbácea dominaría fisionómicamente este paisaje inferido, sobre todo amplios prados de gramíneas de vocación pastoril, lo que daría lugar al desarrollo de un cortejo florístico de elementos antropozoógenos, y otros nitrófilos determinados por la presión antrópica. En la base de la secuencia (ca. 800-415 cal BC según las dataciones obtenidas en PN 2, PN 3 y PN 4) la presión pastoral se produciría en los pastizales cercanos al sitio; mientras en los niveles superiores (ca. 390-205 cal BC de acuerdo a la datación del techo del Escalón II) incluiría el propio yacimiento, con una explotación sostenible del encinar. Esta importancia sustancial de la ganadería, incluso en el interior de los poblados, ha sido demostrada en yacimientos de la Segunda Edad de Hierro, tanto en las estribaciones meridionales de la Sierra de Gredos como en la Meseta Sur (López Sáez et al. 2010a; López Sáez y Pérez Díaz 2012).

Aunque las muestras polínicas estudiadas en PN 1 y la base del Escalón III han resultado estériles, por las fechas radiocarbónicas disponibles (Tab. 2) podríamos asociarlas a la serie inferior de la secuencia, ca. 810-405 cal BC. Aunque para los Escalones I y II no se dispone de fechas ${ }^{14} \mathrm{C}$, la evidente similitud de sus espectros polínicos con los respectivos del techo del Escalón III, datado en ca. 390-205 cal $\mathrm{BC}$, permite asignarles una misma cronología.

Desde un punto de vista paleoclimático, el estudio paleoambiental demuestra la progresiva instalación de condiciones cada vez más húmedas, con el desarrollo de pastizales húmedos y la reducción del pinar altimontano continental.

\section{FAUNA}

\subsection{Vertebrados}

El total de restos de vertebrados recuperados manualmente en la fosa-vertedero asciende a 4.189, excluyendo el nivel más superficial (Escalón I). De este número, 24\% ( $\mathrm{N}=993)$ pudo 
ser identificado taxonómicamente (3) (Tab. 8). El $76 \%$ restante pertenece a fragmentos no determinados de mamíferos de medio y grande porte y pequeñas esquirlas no identificables (4). Junto a los mamíferos se recuperaron dos restos de peces (5), uno de anfibio y cinco de aves.

En las tablas 8 y 9 se presentan la relación del número de restos analizados y la abundancia relativa $(\%)$ de los fragmentos determinados respecto a los indeterminados, así como la de cada una de las especies identificadas en los distintos niveles arqueológicos y el correspondiente número mínimo de individuos (NMI). Para cada especie fueron registrados y cuantificados todos los fragmentos de huesos, dientes y astas/cuernos. Hacemos notar que los dientes se han añadido al NR y que aquellos fragmentos que se han identificado como pertenecientes a un mismo hueso se han contabilizado como un único resto.

Se constata que el NR aumenta de los niveles inferiores a los superiores, siendo el porcentaje de restos identificados progresivamente mayor del PN 4 al Escalón II (PN 4: 19\%, PN 3: 21\%, PN 2: 22\%, PN 1: 23\%, Escalón III: 24\% y Escalón II: 25\%; Tab. 8). En general, como es esperable, las superficies óseas de los restos determinados están mejor conservadas que las de los indeterminados, aunque el índice de fracturas recientes durante la extracción del material es más elevado en la fracción identificada. Las adherencias calcáreas son más abundantes en los niveles superiores (Escalón II, III y PN 1) mientras que el mayor grado de erosión se aprecia entre los restos del PN 3, lo que podría indicar un periodo más prolongado

(3) Las identificaciones se han realizado con ayuda de las colecciones comparativas del Laboratorio de Arqueozoología del CCHS (CSIC-Madrid).

(4) No siempre fue posible llegar a identificaciones específicas, por lo que se crearon categorías artificiales de macroy meso-mamíferos, basadas en el tamaño, en las que se registran fragmentos de cráneo, esquirlas de huesos largos, costillas y vértebras pertenecientes a las especies identificadas. Así, la categoría de macro-mamíferos puede incluir restos de équidos, vacuno y ciervo mientras que la de meso-mamíferos agrupa huesos de animales de medio porte, que en este yacimiento están representados por oveja, cabra, suidos y perro. Los restos de oveja y cabra que no pudieron ser diagnosticados a nivel específico, siguiendo las características señaladas por Boessneck (1969), se agrupan en la categoría de ovicaprino (OC).

(5) Agradecemos la identificación de los restos ícticos a la Dra. Eufrasia Roselló del Laboratorio de Arqueología, de la Universidad Autónoma de Madrid y del único resto de anfibio al Dr. Borja Sanchiz del Museo Nacional de Ciencias Naturales, Madrid. de exposición de estos materiales durante o con anterioridad a su deposición en el foso-vertedero. La frecuencia de huesos mordidos, roídos, con impactos de dientes, probablemente de perro, e incluso digeridos (como por ejemplo, falanges de ovicaprino) varía entre 5\% (Escalón III) y $10 \%$ (PN 3). Estas pequeñas divergencias en los procesos tafonómicos que afectaron a la muestra estudiada no permiten hablar de conservación diferencial entre los distintos estratos, cuya formación responde a la acumulación de materiales de procedencia diversa sobre los que previamente habrían actuado diferentes agentes abióticos y biológicos.

Entre los mamíferos se encuentran representadas al menos 6 especies de Ungulados (6), 3 especies de Carnívoros y 2 especies de Lagomorfos. Ovicaprinos, ganado vacuno, ciervo y conejo son las especies dominantes según el NR y el NMI en el total de la muestra, seguido de los suidos (cerdo doméstico y jabalí). La frecuencia de équidos es más reducida. Completan el espectro faunístico 3 especies de aves: Cuervo (Corvus corax), Corneja negra (Corvus corone) y Perdiz (Alectoris rufa), un anfibio, el Sapo corredor (Epidalea calamita) y 2 especies de peces, Pagrus pagrus y Barbus cf. comizo. El dominio de los Ungulados domésticos (bovino, oveja y cabra) y salvajes (ciervo y jabalí) unido a la baja contribución de los Carnívoros, apenas representados por perro (Canis familiaris), tejón (Meles meles) y oso (Ursus arctos) sugiere el origen doméstico de la asociación, derivada del aprovechamiento y consumo de los varios recursos proporcionados por estas especies.

La mayor diversidad se aprecia en el nivel superior, Escalón II, del que deriva casi la mitad del conjunto total determinado (46\%, Tab. 9). También en este estrato la frecuencia de restos de ganado vacuno (28\%) supera algo la del conjunto de los ovicaprinos (oveja + cabra + O/C 27\%) cuyos restos dominan a lo largo de toda la secuencia (Tab. 9). En la fracción indeterminada la frecuencia mayor de restos de meso-mamíferos frente a los macro-mamíferos, excepto en el PN 1 constituye un indicador más sobre la abundancia de esta cabaña. Dado que la biomasa del vacuno es superior a la de los ovicaprinos se puede concluir

(6) No siempre fue posible obtener la información osteométrica que permite la determinación de especies en el caso de los équidos y los suidos.

Trab. Prehist., 70, N. ${ }^{\circ}$ 1, enero-junio 2013, pp 140-165, ISSN: 0082-5638

doi: $10.3989 /$ tp.2013.12106 


\begin{tabular}{|c|c|c|c|c|}
\hline \multirow{5}{*}{ 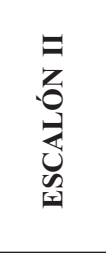 } & & D & I & TOTAL \\
\hline & Aves & 3 & - & 3 \\
\hline & Mamíferos & 452 & 1348 & 1800 \\
\hline & Total & 455 & 1348 & 1803 \\
\hline & $\%$ & 25 & 75 & 43 \\
\hline \multirow{4}{*}{ 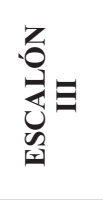 } & Anfibios & 1 & - & 1 \\
\hline & Mamíferos & 179 & 576 & 755 \\
\hline & Total & 180 & 576 & 756 \\
\hline & $\%$ & 24 & 76 & 18 \\
\hline \multirow{3}{*}{ 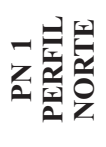 } & Mamíferos & 121 & 399 & 520 \\
\hline & Total & 121 & 399 & 520 \\
\hline & $\%$ & 23 & 77 & 13 \\
\hline \multirow{5}{*}{ 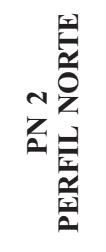 } & Peces & 1 & - & 1 \\
\hline & Aves & 1 & - & 1 \\
\hline & Mamíferos & 119 & 420 & 539 \\
\hline & Total & 121 & 420 & 541 \\
\hline & $\%$ & 22 & 78 & 13 \\
\hline \multirow{4}{*}{ 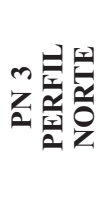 } & Peces & 1 & - & 1 \\
\hline & Mamíferos & 74 & 280 & 354 \\
\hline & Total & 75 & 280 & 355 \\
\hline & $\%$ & 21 & 79 & 8 \\
\hline \multirow{6}{*}{ 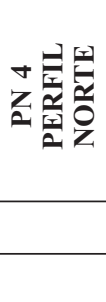 } & Aves & 1 & - & 1 \\
\hline & Mamíferos & 40 & 173 & 213 \\
\hline & Total & 41 & 173 & 214 \\
\hline & $\%$ & 19 & 81 & 5 \\
\hline & TOTAL & 993 & 3196 & 4189 \\
\hline & $\%$ & 24 & 76 & \\
\hline
\end{tabular}

Tab. 8. Número y porcentaje de restos faunísticos determinados (D) e indeterminados (I) del Cerro de la Mesa.

que su aportación cárnica debió ser mayor que la de ovejas y cabras. Sin embargo, su contribución no es tan regular como la del ciervo, que apenas varía entre los diferentes niveles (PN 4: 17\%, PN 3: $19 \%$, PN 2: 18\%, PN 1: 19\%, Escalón III: $11 \%$ y Escalón II: 18\%). Además, los valores obtenidos para los Lagomorfos, en particular el conejo, los dos restos de perdiz en PN 4 y PN 2, así como los dos restos ícticos en PN 2 y PN 3 corroboran la explotación del entorno natural, quizás de forma estacional, y el papel destacado que la actividad cinegética, y en menor medida la pesca, habrían desempeñado en la alimentación de la población asentada en este espacio, cuyo modo de subsistencia se basaría en actividades agropastoriles y ganaderas.

En el total del conjunto se da un predominio de los animales domésticos con un 66\% según el NR, sobre los salvajes con un 34\%. Esta tendencia se mantiene a lo largo de toda la secuencia arqueológica, evidenciándose la mayor contribución de animales cazados en el PN $1(40 \%)$ y la menor en el estrato inferior PN 4 (25\%), que por otro lado es también la asociación más pobre. A pesar de las diferencias existentes en la cantidad de material recuperado tampoco se observan variaciones apreciables en las porciones anatómicas de los taxones principales que se encuentran representados desde el esqueleto craneal a la parte inferior del esqueleto apendicular.

El tamaño reducido de las muestras recuperadas, a excepción del nivel superior (Escalón II) y el carácter secundario del depósito imponen cautela a la hora de obtener información sobre la gestión de las diferentes cabañas domésticas que nos permita evaluar los modelos de producción desarrollados con anterioridad al establecimiento del poblado vettón.

La determinación de la edad de sacrificio (7) de la cabaña bovina indica la preferencia por animales adultos (mayores de 6 años de edad), aunque en los tres niveles superiores también se constataron al menos tres individuos inmaduros (de entre 18-30 meses de edad). Este patrón refleja un doble aprovechamiento en el que el interés económico de las reses en las labores agrícolas, tanto por su fuerza de trabajo como por el estiércol que proporcionan (Moreno-García y Pimenta 2011), tendría prioridad sobre la cría orientada a la producción cárnica. En los ovicaprinos se detecta un patrón de mortalidad en el que destacan la cohorte juvenil compuesta por animales menores de 2 años de edad y los animales maduros con más de 6 años, lo que sugiere la explotación cárnica de individuos que han alcanzado su peso óptimo y el mantenimiento hasta agotar su vida fértil, presumiblemente de hembras, de las cuales se obtienen también leche, lana y abono.

(7) La determinación de la edad de sacrificio se ha calculado a partir del estado de erupción dentaria y del desgaste de los molares inferiores (Payne 1973; Grant 1982; Jones y Sadler 2012), así como del estado de fusión ósea (Silver 1969). 


\begin{tabular}{|c|c|c|c|c|c|c|c|c|c|c|c|c|c|c|c|c|c|c|}
\hline & & EQU & BOS & OVA & $\mathrm{CAH}$ & $\mathrm{OC}$ & SUS & CEE & LEP & ORC & Lag. & CAF & MEL & Car. & URA & OTROS & NTOTAL & $\%$ \\
\hline \multirow{6}{*}{ = } & Huesos & 13 & 91 & 12 & 5 & 65 & 14 & 70 & 1 & 56 & 1 & - & 1 & 1 & 1 & 3 aves & 334 & 73 \\
\hline & Dientes & 1 & 34 & 6 & 8 & 28 & 7 & 9 & - & 19 & - & - & - & - & - & - & 112 & 25 \\
\hline & Cuernos/Astas & - & 5 & 2 & - & - & - & 2 & - & - & - & - & - & - & - & - & 9 & 2 \\
\hline & Total restos & 14 & 130 & 20 & 13 & 93 & 21 & 81 & 1 & 75 & 1 & - & 1 & 1 & 1 & 3 & 455 & 46 \\
\hline & $\% \mathrm{NR}$ & 3 & 28 & 4 & 3 & 20 & 5 & 18 & $<1$ & 16 & $<1$ & - & $<1$ & $<1$ & $<1$ & $<1$ & & \\
\hline & NMI & 2 & 4 & 2 & 2 & 5 & 2 & 2 & 1 & 5 & & - & 1 & & 1 & 2 & 29 & \\
\hline \multirow{6}{*}{ 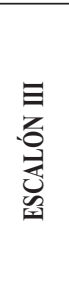 } & Huesos & 2 & 21 & 2 & 4 & 30 & 10 & 17 & 2 & 30 & 4 & 1 & - & 1 & - & $1 \mathrm{anf}$ & 125 & 69 \\
\hline & Dientes & - & 5 & 3 & 7 & 25 & 7 & 3 & - & 3 & - & - & - & - & - & - & 53 & 29 \\
\hline & Cuernos/Astas & - & 2 & - & - & - & - & - & - & - & - & - & - & - & - & - & 2 & 1 \\
\hline & Total restos & 2 & 28 & 5 & 11 & 55 & 17 & 20 & 2 & 33 & 4 & 1 & - & 1 & - & 1 & 180 & 18 \\
\hline & $\% \mathrm{NR}$ & 1 & 16 & 3 & 6 & 30 & 9 & 11 & 1 & 18 & 2 & $<1$ & - & $<1$ & - & $<1$ & & \\
\hline & NMI & 1 & 2 & 1 & 3 & 3 & 3 & 1 & 1 & 4 & & 1 & - & & 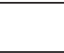 & 1 & 21 & \\
\hline \multirow{6}{*}{ 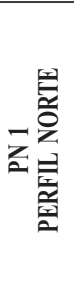 } & Huesos & 1 & 18 & 1 & 1 & 15 & 5 & 19 & 1 & 15 & - & 3 & - & - & - & - & 79 & 65 \\
\hline & Dientes & - & 10 & - & 1 & 12 & 4 & 2 & - & 8 & - & - & - & - & - & - & 37 & 31 \\
\hline & Cuernos/Astas & - & 1 & - & 2 & - & - & 2 & - & - & - & - & - & - & - & - & 5 & 4 \\
\hline & Total restos & 1 & 29 & 1 & 4 & 27 & 9 & 23 & 1 & 23 & - & 3 & - & - & - & - & 121 & 12 \\
\hline & $\% \mathrm{NR}$ & 1 & 24 & 1 & 3 & 22 & 7 & 19 & 1 & 19 & - & 2 & - & - & - & - & & \\
\hline & NMI & 1 & 2 & 1 & 1 & 2 & 2 & 1 & 1 & 3 & & 1 & - & & - & & 15 & \\
\hline \multirow{6}{*}{ 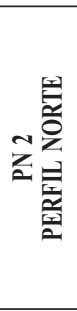 } & Huesos & 5 & 10 & 2 & 1 & 17 & 12 & 9 & - & 8 & - & - & - & - & - & $\begin{array}{l}1 \text { ave, } \\
1 \text { pez }\end{array}$ & 66 & 54 \\
\hline & Dientes & 2 & 5 & - & 1 & 15 & 17 & 13 & - & 1 & - & 1 & - & - & - & - & 55 & 46 \\
\hline & Cuernos/Astas & - & - & - & - & - & - & - & - & - & - & - & - & - & - & - & - & - \\
\hline & Total restos & 7 & 15 & 2 & 2 & 32 & 29 & 22 & - & 9 & - & 1 & - & - & - & 2 & 121 & 12 \\
\hline & $\% \mathrm{NR}$ & 6 & 12 & 2 & 2 & 27 & 24 & 18 & - & 7 & - & 1 & - & - & - & 1 & & \\
\hline & NMI & 1 & 1 & 1 & 1 & 3 & 2 & 1 & - & 2 & & 1 & - & & - & 2 & 15 & \\
\hline \multirow{6}{*}{ 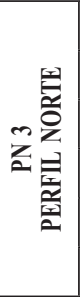 } & Huesos & - & 11 & 4 & 1 & 16 & 2 & 8 & 2 & 6 & - & 1 & 1 & - & - & $1 \mathrm{pez}$ & 53 & 71 \\
\hline & Dientes & 1 & 3 & - & - & 6 & 4 & 1 & - & - & - & - & - & - & - & - & 15 & 20 \\
\hline & Cuernos /Astas & - & 1 & - & - & 1 & - & 5 & - & $*_{-}$ & - & - & - & - & - & - & 7 & 9 \\
\hline & Total restos & 1 & 15 & 4 & 1 & 23 & 6 & 14 & 2 & 6 & - & 1 & 1 & - & - & 1 & 75 & 7,5 \\
\hline & $\% \mathrm{NR}$ & 1 & 20 & 5 & 1 & 31 & 8 & 19 & 3 & 8 & - & 1 & 1 & - & - & - & & \\
\hline & NMI & 1 & 1 & 1 & 1 & 2 & 1 & 2 & 1 & 2 & & 1 & 1 & & - & 1 & 15 & \\
\hline \multirow{9}{*}{ 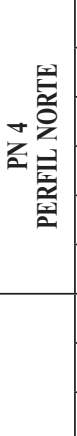 } & Huesos & - & 4 & 2 & 1 & 4 & 6 & 7 & - & 3 & - & - & - & - & - & 1 ave & 28 & 68 \\
\hline & Dientes & - & - & 3 & - & 3 & 3 & - & - & - & - & - & - & - & - & - & 9 & 22 \\
\hline & Cuernos/Astas & - & 2 & - & 2 & - & - & - & - & - & - & - & - & - & - & - & 4 & 10 \\
\hline & Total restos & - & 6 & 5 & 3 & 7 & 9 & 7 & - & 3 & - & - & - & - & - & 1 & 41 & 4 \\
\hline & $\% \mathrm{NR}$ & - & 15 & 12 & 7 & 17 & 22 & 17 & - & 7 & - & - & - & - & - & 2 & & \\
\hline & NMI & - & 1 & 1 & 2 & 2 & 1 & 2 & - & 1 & & - & - & & - & 1 & 11 & \\
\hline & TOTAL & 25 & 223 & 37 & 34 & 237 & 91 & 167 & 6 & 149 & 5 & 6 & 2 & 2 & 1 & 8 & 993 & \\
\hline & $\%$ NR & 2,5 & 22,5 & 4 & 3,5 & 24 & 9 & 17 & 1 & 15 & $<1$ & 1 & $<1$ & $<1$ & $<1$ & 1 & 100 & \\
\hline & NMI & 6 & 11 & 7 & 10 & 17 & 11 & 9 & 4 & 17 & & 4 & 2 & & 1 & 7 & 106 & \\
\hline
\end{tabular}

Tab. 9. Relación de huesos, dientes y cuernos/astas de mamíferos y otros vertebrados identificados en el foso-vertedero (Corte 6) de El Cerro de la Mesa. Abreviaturas: EQU: équido; BOS: vacuno; OVA: oveja; CAH: cabra; OC: ovicaprino; SUS: cerdo/jabalí; CEE: ciervo; LEP: liebre; ORC: conejo; Lag: liebre/conejo; CAF: perro; MEL: tejón; Car: carnívoro; URA: oso. NMI: número mínimo de individuos.

Trab. Prehist., 70, N. ${ }^{\circ}$ 1, enero-junio 2013, pp 140-165, ISSN: 0082-5638 doi: $10.3989 /$ tp.2013.12106 
La distinción entre oveja y cabra solo fue posible en un pequeño número de restos. La relación entre las dos especies se mantiene equilibrada a lo largo de la secuencia estratigráfica lo cual permite suponer que ambas cabañas se mantuvieron en las mismas proporciones, aunque si consideramos el NMI total el ganado caprino supera al ovino. En este sentido, resulta interesante apuntar que $50 \%$ de las cabras identificadas corresponden a individuos menores de un año, mientras que en las ovejas este porcentaje es de $28 \%$. En términos económicos esta diferencia puede indicar la explotación preferencial del ganado caprino para carne y leche, en cuanto en el ovino pudo haber un aprovechamiento más generalizado de todos los recursos disponibles.

Entre la pequeña muestra de suidos hay un claro predominio de ejemplares jóvenes, aunque no se recuperaron restos de neonatos. El aprovechamiento pecuario del ganado porcino es primario. La existencia de restos de animales adultos confirma la reproducción local y el tamaño de un metatarso en PN 1 la caza ocasional de jabalí.

La baja contribución de los équidos evidencia el papel marginal que tuvieron dentro de la cabaña doméstica, al mismo tiempo que refuerza el carácter doméstico de desechos alimentarios de la muestra recuperada. La ausencia de huellas de manipulación refrenda que contribuyeron en poco o nada a la dieta. Apenas dos piezas (un calcáneo en Escalón II y una tibia en Escalón III) pertenecen a individuos subadultos. Por el contrario, el ciervo sería el taxón más importante en la dieta, tras el vacuno y los ovicaprinos, y por delante de la cabaña porcina, ya que todos los restos con excepción de cuatro (recuperados en el nivel superior Escalón II) pertenecen a ejemplares adultos, cuyo valor a efectos de aporte cárnico sería elevado. La alta frecuencia de restos craneales $(31 \%$ del NR total) y huesos distales de las patas (tarsales, carpales, metápodios y falanges representan 50\% del NR total) sugieren el transporte de carcasas completas desde el lugar de caza al de consumo.

Lamentablemente las alteraciones tafonómicas ya señaladas impidieron la observación de huellas en gran parte de la muestra. Sí se reconocieron incisiones superficiales en las diáfisis y cortes profundos en las zonas de articulación de los huesos largos, escápulas y pelvis, como consecuencia del fileteado de carne y el despiece de las carcasas. Además, algunos fragmentos de asta presentaban cortes paralelos relacionados con la utilización de este material como materia prima. A este propósito, recordemos las dos piezas de industria ósea (en PN 2 y PN 3) manufacturadas sobre tibias de ovicaprino a las que se habían retirado las zonas de articulación proximal y distal y que presentaban bordes pulidos y decoración incisa a lo largo de sus diáfisis (Fig. 9: 2 y 3).

$\mathrm{La}$ actividad cinegética se complementa con los Lagomorfos, especialmente a partir del PN 1 cuando se observa una tendencia hacia su aumento. La práctica ausencia de individuos inmaduros y piezas articuladas parecen excluir que sean elementos intrusivos.

En conclusión, y con la precaución que imponen las características de la asociación estudiada desde el punto de vista cuantitativo y cualitativo (material de relleno en contexto secundario), el análisis arqueozoológico ha permitido documentar cuáles fueron los recursos animales explotados durante la ocupación pre-vettona en el Cerro de la Mesa. No se aprecian variaciones significativas en la composición faunística a lo largo de la secuencia estratigráfica identificada. Junto a la explotación ganadera de bovinos y ovicaprinos a escala doméstica, combinando el consumo cárnico y el aprovechamiento de productos secundarios, destaca el aporte de la caza mayor, en especial de venados. Además la presencia de otras especies silvestres como la liebre, el jabalí, la perdiz o incluso el oso evidencian la explotación de un entorno natural caracterizado por espacios mosaico en los que la cobertura arbórea alternaría con zonas más abiertas. Cabría preguntarse si el importante componente cinegético registrado responde a un consumo estacional complementario de los recursos derivados de las actividades agropecuarias, que sin duda constituían la base económica de las comunidades aquí asentadas o si pudiera reflejar diferencias de orden socio-económico entre grupos de población. La respuesta a estos interrogantes solo será posible a través del estudio de otras muestras procedentes de contextos similares de la Edad del Hierro.

\subsection{Moluscos}

Los restos recuperados son en su mayoría conchas de náyades, es decir, de bivalvos de agua dulce del Orden Unionoida, de los que aparecen 
representantes de dos familias: Margaritiferidae y Unionidae (Tab. 10). Sorprende la cantidad de restos de Margaritifera auricularia, especie hoy casi extinguida en la Península Ibérica a excepción del cauce principal del río Ebro en Aragón y Tarragona y Canales Imperial de Aragón y de Tauste (Aragón y Navarra) (Araujo y Ramos 2000; Gómez y Araujo 2008). Está también extinguida en toda su área de distribución original (Paleártico oeste) salvo en los ríos Loire y Charente en Francia (Nienhuis 2003). Actualmente, la población más numerosa del planeta parece ser la que vive en el Canal Imperial de Aragón, en la provincia de Zaragoza, con aproximadamente 3.500 ejemplares (Araujo et al. 2009). Existe una cita de 1903 del río Tajo en Toledo (Azpeitia 1933) y se han encontrado valvas de ejemplares muertos en las últimas décadas en el Ebro en Burgos, Álava, La Rioja y Navarra (Araujo et al. 2007). También se ha citado su presencia en yacimientos arqueológicos desde el año 5000 a.C. hasta el 400 d.C en cuatro cuencas hidrográficas ibéricas: Duero, Tajo, Ebro y Guadalquivir (Araujo y Moreno 1999). Las causas fundamentales de su progresiva desaparición son el deterioro de sus hábitats (detracciones de agua, alteración de los caudales y flujos por las centrales hidroeléctricas y riegos, aumento exponencial de industrias contaminantes y cultivos), así como el aumento de especies de peces y bivalvos invasores.

Una de las características principales de las náyades es su ciclo vital, ya que presentan un estado larvario singular denominado gloquidio, que requiere la presencia de un pez hospedador en el que, tras una metamorfosis, se produce la fase juvenil. En un ecosistema sin modificar, estos moluscos son el grupo de animales con mayor biomasa. Intervienen además en la dinámica de los nutrientes de los sistemas acuáticos, removiendo fitoplancton, bacterias y materia orgánica del agua y sedimento y colaboran en la bioturbación de los fondos aumentando su contenido de oxígeno (Strayer et al. 1999; Vaughn et al. 2008). Dado que una náyade filtra hasta 50 litros diarios de agua, y que pueden vivir en colonias de hasta 700 ejemplares por $\mathrm{m}^{2}$, en ese tramo de río se filtrarían hasta 35.000 litros por día. Son además especies con un alto poder bioindicador, lo que probablemente ha querido reflejar el nombre de náyade, ya utilizado por el Caballero Jean-Baptiste Lamarck (1744-1829) para referirse a estos bivalvos, alu-

\begin{tabular}{|c|c|c|c|c|c|}
\hline \multirow{2}{*}{ CONCHAS } & \multicolumn{2}{|c|}{$\begin{array}{c}\text { M. } \\
\text { auricularia }\end{array}$} & \multicolumn{2}{|c|}{ P. littoralis } & \multirow{2}{*}{$\boldsymbol{R}$. decollata } \\
\cline { 2 - 5 } & VD & VI & VD & VI & \\
\hline ESCALÓN II & 1 & 2 & 2 & 2 & 18 \\
\hline ESCALÓN III & 2 & 1 & 1 & 2 & 8 \\
\hline
\end{tabular}

Tab. 10. Clasificación de la muestra de conchas. $\mathrm{VD}=$ Valva derecha; VI = Valva Izquierda. Estas piezas estaban prácticamente completas. $\mathrm{M}=$ Margaritifera $; \mathrm{P}=$ Potomida $; \mathrm{R}=$ Rumina .

diendo a las hadas o ninfas que mantienen la pureza de las aguas dulces. De este modo, la presencia (o la desaparición documentada) de poblaciones reproductoras (con ejemplares juveniles) de estos moluscos, puede ser de gran utilidad para conocer cambios en el estado de calidad y conservación de las aguas superficiales, lo que hace de las náyades excelentes especies centinelas.

Hay también restos de otra náyade, Potomida littoralis (Cuvier 1798), que aunque también en recesión, mantiene poblaciones vivas en prácticamente todas las cuencas ibéricas (Araujo et al. 2009). Por último, aparecen gasterópodos terrestres de la especie Rumina decollata (Linnaeus, 1758).

\section{CONCLUSIONES}

La información obtenida durante la excavación del relleno de la fosa permite interpretarla como un vertedero de tierra, cenizas, materiales fragmentados y fauna, que se corresponde con la limpieza y posterior enrasado de la zona sureste del cerro para su posterior urbanización. Dado que las viviendas inmediatamente superpuestas a la fosa han sido fechadas por sus materiales en el siglo II a.C. (Almagro-Gorbea et al. 1999: 163; Chapa et al. 2007) esta acción debió ocurrir a finales del siglo III o inicios del siglo II a.C.

Las fechas radiocarbónicas obtenidas en la secuencia no son precisas, como es habitual para la época en la que nos movemos (Rubinos Pérez et al. 1999: 149). En cualquier caso, casi todas se concentran en las fases más antiguas de la ocupación del yacimiento (siglo VII a V a.C.), correspondientes a la construcción de la muralla, el

Trab. Prehist., 70, N. ${ }^{\circ}$ 1, enero-junio 2013, pp 140-165, ISSN: 0082-5638

doi: $10.3989 /$ tp.2013.12106 
santuario y las primeras etapas del poblado intramuros. Este punto se confirma a través de los materiales cerámicos. Las cerámicas a peine, mangos de hueso, etc, nos indican que también se desmontaron estructuras del siglo IV y III a.C. cuya existencia queda confirmada por los fragmentos áticos recuperados durante las excavaciones anteriores en los rellenos de tierra de las viviendas (Ortega y Valle 2004: 179). En líneas generales, las cerámicas recuperadas en la fosa parecen revelar una cierta contaminación de los niveles que alteran, especialmente en las cotas más bajas, donde hay más cerámicas antiguas, vinculadas al poblado del siglo V a.C. Sin embargo, estos fragmentos se mezclaron con producciones más tardías que vendrían de otros niveles y áreas del yacimiento en curso de desmantelamiento.

Los muros y materiales correspondientes al asentamiento del siglo V a.C. marcaron el límite de profundización de la fosa, sin que se aprecien restos de estructuras de las etapas más recientes. Esto permite plantear la hipótesis de que el vertedero se situara en un área no habitada a partir de esa fecha. Tanto el tamaño de la fosa como el volumen de materiales vertidos en ella resultan significativos de una obra de envergadura. Guiándonos por el número de restos encontrados en nuestra más que limitada excavación y proyectando estos datos al área total que consideramos ocupada por este vertedero, se habrían vertido en su interior en torno a 40.000 fragmentos cerámicos, lo que supondría más de $600 \mathrm{~kg}$ de peso. En cuanto a la fauna, la previsión sería de cerca de 10.000 fragmentos óseos.

La deposición de los restos fue cuidadosa y sistemática. No hay materiales constructivos a excepción de algunos fragmentos aislados de adobe, y tanto la fauna como la cerámica van envueltos en una matriz de tierra suelta, cenizas y carbones. La fragmentación es el rasgo común con pequeñas excepciones, como uno de los mangos de hueso. Los restos de fauna, a menudo partidos longitudinalmente, y muchos de los fragmentos cerámicos, se colocaron horizontalmente, como para regularizar el depósito. Consideramos que la excavación de la fosa y su progresivo relleno se produjo con cierta rapidez, recuperándose los desechos de las estructuras, probablemente arruinadas, que ocupaban distintas zonas del asentamiento. El hecho de que algunos restos de fauna presenten mordeduras podría indicar que los fragmentos pasaron un cier- to tiempo al aire libre, aunque es más probable que aquellas se produjeran en el momento original de su aprovechamiento.

A pesar de que los materiales se depositaran en la fosa en un momento tardío, su estudio no deja de informarnos sobre las características de la sociedad que habitó este asentamiento entre el siglo VII a.C. y el II a.C. El entorno, dominado por un encinar aclarado y alcornoques que permiten el aprovechamiento del corcho, va dando paso a un paisaje de herbáceas que revela la importancia de la ganadería, básicamente de bovinos y ovicaprinos si atendemos a los restos óseos. Sin embargo, llama la atención la fuerte incidencia de la caza, especialmente de los venados, aunque también jabalíes, liebres, perdices e incluso oso. Todo ello es coherente con la información sobre las especies de caza que podían obtenerse en este sitio en fechas históricas: el Libro de la Montería de Alfonso XI indica que era un lugar adecuado para la caza del oso y del jabalí todavía en el siglo XIV (8). Por su parte, el empleo de peces y náyades no solo revela el aprovechamiento de los recursos fluviales, sino en el caso de las segundas, la buena calidad de sus aguas.

Las fosas rellenas de niveles arcillosos y/o cenicientos están documentadas hace tiempo en múltiples yacimientos de la Segunda Edad del Hierro de la Meseta Norte. En un principio se las consideró características de la región vaccea y después, de la cuenca del Duero en general (San Miguel Maté 1993: 38; Álvarez Sanchís 2003: 151; García Sánchez 2012: 213-222), pero en la actualidad sabemos que se extendieron también por el área vettona vinculada a la cuenca del Tajo, incluyendo Toledo y Cáceres. La excavación de los casos de Simancas (Wattenberg 1978) y Castrojeriz (Abásolo et al. 1983) estableció sus principales características, que se repiten rigurosamente en todos los ejemplos conocidos: estructuras negativas de gran magnitud, rellenas de depósitos marcadamente horizontales, que contienen sobre todo fragmentos cerámicos y restos faunísticos, así como escasos materiales constructivos. Aunque pueda haber diferencias cronológicas entre los objetos recuperados, sus características revelan un proceso de formación rápido, probablemente como

(8) Alfonso XI. Libro de la Montería. Ediciones Velázquez. Madrid, 1976. Introducción de Jesús E. Casariego. Versión y notas de José Gutiérrez de la Vega: 237-238. 
consecuencia de una remodelación en profundidad de los niveles previos de hábitat con vistas a un replanteamiento urbanístico.

Esta caracterización, realizada a raíz de las citadas excavaciones en Castrojeriz (Abásolo et al. 1983: 292), puede aplicarse sin apenas modificaciones al Cerro de la Mesa, que a su vez, y por los indicios disponibles, tiene sus paralelos más cercanos en yacimientos cacereños. La escasa información que hasta el momento ha aportado el Castro de Villasviejas del Tamuja (Ongil 1991: 250) refleja la existencia de uno de estos vertederos colmatando una zona de muralla, con el fin de construir encima. En el Castro de La Coraja, en Aldeacentenera, la relación con la muralla se repite y la configuración faunística, a pesar de no estar publicada con detalle, parece incluir sobre todo fauna de mamíferos, acompañada de peces y moluscos de río, al igual que en el Cerro de la Mesa (Redondo Rodríguez y Esteban Ortega 1992-1993: 171-172).

Las interpretaciones que se han dado a estos vertederos rellenos de sedimentos con cerámica, fauna y algunos otros elementos, han sido fundamentalmente dos. Una de ellas las relaciona con posibles actividades de mercado, con la consiguiente afluencia de personas y aumento del consumo, lo que conduciría a la generación de importantes cúmulos de basura cerámica y explicaría el alto volumen de fauna que se suele recuperar en su interior. Así se ha propuesto entender la enorme fosa localizada en Las Cogotas, cuyos sedimentos alcanzan hasta $3 \mathrm{~m}$ de altura (Álvarez Sanchís 2011: 169). La segunda, ya citada, las conecta con una remodelación urbanística de los poblados. El deseo de asentar un nuevo trazado urbano habría llevado a la excavación de las fosas para rellenarlas con elementos desechables, como pequeños restos constructivos, cerámica fragmentada y fauna en abundancia. La construcción inmediata de una serie de viviendas y viales tras la colmatación de la fosa en el Cerro de la Mesa, nos hace preferir esta segunda opción (San Miguel Maté 1993: 39).

Para explicar la selección de componentes que conforman el relleno de estos depósitos puede ser interesante recurrir a las notas publicadas por Cabré a raíz de sus trabajos en Las Cogotas. La excavación de las casas vettonas hasta la roca madre le reveló que el sistema para regularizar el suelo antes de su construcción, era introducir "piedras, tierras carbonizadas, gran cantidad de despojos de cocina y huesos en abundancia, algunos de ellos de mucho tamaño... con los que alternan numerosos fragmentos de cerámica" (Cabré 1930: 38). Por tanto, podría proponerse que, en caso de una remodelación urbanística en profundidad, las fosas podrían haberse rellenado con este tipo de restos procedentes del desmantelamiento de las viviendas previas. Los materiales constructivos de más envergadura, como las piedras de los zócalos, las maderas, los objetos valiosos o en buen estado, se habrían reutilizado, y otros elementos sobrantes se pudieron arrojar a vertederos extramuros.

La fosa-vertedero del Cerro de la Mesa parece indicar un patrón de comportamiento urbanístico ligado a la reocupación de estos poblados o a su replanteamiento urbanístico a comienzos del siglo II a.C., cuando se desarrollan las ciudades en el mundo vettón (Álvarez Sanchís 2011: 148). La remodelación del Cerro de la Mesa conducirá a la construcción de un gran número de viviendas y viales de comunicación, en los que se desarrollará una activa vida social y económica planteada a largo plazo, aunque los acontecimientos provocarán el abandono final del asentamiento a finales del siglo I a.C. A la luz de los datos presentados, este proceso urbanizador adquiere una notable expansión, ya que lejos de limitarse a la cuenca del Duero, sobrepasa el Sistema Central y se extiende también al curso del Tajo, penetrando desde Toledo hacia Extremadura y revelando la notable personalidad y dinamismo de los grupos vettones.

\section{AGRADECIMIENTOS}

Este trabajo se enmarca en el proyecto HAR2011/25191: "Identidad y territorio en el valle medio del Tajo durante el Bronce Final y la Edad del Hierro" del Ministerio de Economía y Competitividad. Agradecemos a los revisores externos sus anotaciones, que han mejorado sensiblemente la primera versión de este trabajo.

\section{BIBLIOGRAFÍA}

Abásolo, J. A.; Ruiz, I. y Pérez F. 1983: "Castrojeriz I: el vertedero de la Colegiata". Noticiario Arqueológico Hispanico 17. Madrid: 191-318. 
Alfayé Villa, S. 2010: “Iconografía vaccea: una aproximación a las imágenes del territorio vacceo". En F. Romero Carnicero y C. Sanz Mínguez (eds): De la Región Vaccea a la Arqueología Vaccea. Centro de Estudios Vacceos 'Federico Wattenberg', Universidad de Valladolid. Valladolid: 547-573.

Almagro Gorbea, M.; Cano Martín, J. J. y Ortega Blanco, J. 1999: "El anillo argénteo del Cerro de la Mesa (Toledo) y los anillos con caballito de la Hispania prerromana". Complutum 10: 157-166.

Alonso, P. y Benito, J. E. 1992: "Una cabeza de caballo procedente del Castro de Las Cogotas (Cardeñosa, Avila)". Trabajos de Prehistoria 49: 365-372.

Álvarez Sanchís, J. R. 2003: Los Vettones. Real Academia de la Historia. Madrid.

Álvarez Sanchis, J. R. 2011: "Ciudades vettonas". En J. Álvarez Sanchis, A. Jimeno Martínez y G. Ruiz Zapatero (eds.): Aldeas y ciudades en el primer milenio a.C. La Meseta Norte y los orígenes del urbanismo. Complutum 22 (2): 147-183.

Andrade, A.; Valdeolmillos, A. y Ruiz Zapata, M. B. 1994: "Modern spectra and contemporary vegetation in the Paramera Range (Ávila, Spain)". Review of Palaeobotany and Palynology 82: 127-139.

Araujo, R.; Madeira, M. y Ayala, I. 2007: Estudio del estado actual de Margaritifera auricularia en las aguas del río Ebro. Confederación Hidrográfica del Ebro. Zaragoza.

Araujo, R. y Moreno, R. 1999: "Former Iberian distribution of Margaritifera auricularia (Spengler) (Bivalvia: Margaritiferidae)". Iberus 17 (1): 127-136.

Araujo, R. y Ramos, M.A. 2000: "Status and conservation of the relict giant European freshwater pearl mussel Margaritifera auricularia (Spengler, 1793)". Biological Conservation 96 (2): 233-239.

Araujo, R.; Reis, J.; Machordom, A.; Toledo, C.; Madeira, M. J.; Gómez, I.; Velasco, J. C.; Morales, J.; Barea, J. M.; Ondina, P. y Ayala, I. 2009: "Las náyades de la Península Ibérica". Iberus 27 (2): 7-72.

Azpeitia, F. 1933: Conchas bivalvas de agua dulce de España y Portugal. Memorias del Instituto Geológico y Minero de España, Madrid. 2 vols.

Behre, K. E. 1981: "The interpretation of anthropogenic indicators in pollen diagrams". Pollen et Spores 23: 225-245.

Belén Deamos, M. 2006: "Ánforas de los siglos VI-IV a.C. en Turdetania”. SPAL 15: 217-246.

Blanco, J. F. 2003: "Iconografía del caballo entre los pueblos prerromanos del centro-norte de Hispania". En F. Quesada y M. Zamora (eds.): El caballo en la antigua Iberia. Bibliotheca Archaeologica Hispana 19, Real Academia de la Historia. Madrid: 75-123.

Boessneck, J. 1969: "Osteological differences between sheep and goats". En D. Brothwell y E. S. Higgs (eds.): Science in Archaeology. Thames and Hudson. Londres: 331-358.

Burjachs, F.; López Sáez, J. A. e Iriarte, M. J. 2003: "Metodología Arqueopalinológica". En R. Buxó y R.
Piqué (eds.): La recogida de muestras en Arqueobotánica: objetivos y propuestas metodológicas. La gestión de los recursos vegetales y la transformación del paleopaisaje en el Mediterráneo occidental. Museu d'Arqueologia de Catalunya. Barcelona: 11-18.

Cabré, J. 1930: Excavaciones en Las Cogotas. Cardeñosa (Ávila) I. El Castro. Memorias de la Junta Superior de Excavaciones y Antigüedades 110 ( ${ }^{\circ}$ 6 de 1929). Madrid.

Cabré, J. 1932: Excavaciones en Las Cogotas (Cardeñosa, Ávila) II. La necrópoli. Memorias de la Junta Superior de Excavaciones y Antigüedades 120 (n4 de 1931). Madrid.

Cabré, J.; Cabré, M. E. y Molinero A. 1950: El Castro y la Necrópolis del Hierro Céltico de Chamartín de la Sierra (Ávila). Acta Arqueológica Hispana V, Ministerio de Cultura. Madrid.

Castelo Ruano, R.; López Sáez, J. A.; López Pérez, A. M.; Peña Chocarro, L.; Ruiz Alonso, M.; López Merino, L.; Pérez Díaz, S.; Liesau, C.; García Giménez, R.; Gómez, J. L. y Manglano, G. 2010-2011: “Una aproximación interdisciplinar a las actividades agropecuarias y cinegéticas de un asentamiento rural lusitano: El Saucedo (Talavera la Nueva, Toledo)". Boletín de la Asociación Española de Amigos de la Arqueología 46: 205-236.

Chapa Brunet, T. y Pereira Sieso, J. 2006: "Un vado perdido: el Cerro de la Mesa (Alcolea de Tajo, Toledo)". Miscelánea en homenaje a Victoria Cabrera. Zona Arqueológica 7, II, Museo Arqueológico Regional. Alcalá de Henares: 120-133.

Chapa Brunet, T.; Pereira Sieso, J.; Madrigal Belinchón, A.; Perlines, M.; Fernández del Cerro, J.; Arcos Lamarca, L. de y Charro Lobato, C. 2007: "El asentamiento protohistórico del Cerro de la Mesa (Alcolea de Tajo, Toledo)". En J. M. Millán Martínez y C. Rodríguez Ruza (eds.): Arqueología de Castilla-La Mancha I. Jornadas (Cuenca 2005): 797-809. Cuenca.

Charro, C.; Chapa, T. y Pereira, J. 2009: "Intervenciones arqueológicas en el Cerro de la Mesa (Alcolea de Tajo, Toledo). Campañas 2005-2007'. En P. J. Sanabria Marcos (ed.): Los pueblos prerromanos en la actual demarcación Beira Baixa - Alto Alentejo - Cáceres. Memorias 9, Publicaciones del Museo de Cáceres. Cáceres: 131-139.

Cuvier, G. 1798: Tableau Elémentaire de l'Histoire Naturelle des Animaux. Baoudin. Madrid, 710.

Fernández Gómez, F. 1986: Excavaciones arqueológicas en El Raso de Candeleda (Ávila) I y II. Instituto Gran Duque de Alba, Diputación Provincial de Ávila. Ávila.

Franco Múgica, F. 2009: “El análisis polínico en la reconstrucción del paisaje vegetal". En M. Génova, F. Gómez-Manzaneque y C. Morla-Juaristi (eds.): Los bosques de Gredos a través del tiempo. Junta de Castilla y León. Valladolid: 89-117.

García Sánchez, J. 2012: Arqueología y Paisaje en el noroeste de Burgos: la transición de la Segunda 
Edad del Hierro a época romana a través del registro material. Tesis Doctoral. Universidad de Cantabria. Santander. http://www.tdx.cat/handle/10803/80486 (consulta: 14-I-2013).

Gómez, I. y Araujo, R. 2008: "Channels and ditches as the last shelter for freshwater mussels. The case of $M$. auricularia and other naiads at the mid Ebro River basin, Spain". Aquatic Conservation: Marine and Freshwater Ecosystems 18: 658-670.

Grant, A. 1982: "The use of tooth wear as a guide to the age of domestic ungulates". En B. Wilson, C. Grigson y S. Payne (eds.): Ageing and sexing animal bones from archaeological sites. British Archaeological Reports, British Series 109, Archaeopress. Oxford: 91-108.

Hernández Carretero, A. M. 1993: “Contribución al estudio de las relaciones culturales durante la II Edad del Hierro en la Cuenca Media del Guadiana: la cerámica gris". Norba. Revista de Historia 13: 39-61.

Jones, G. G. y Sadler, P. 2012: "Age at death in cattle: methods, older cattle and known-age reference Material". Environmental Archaeology 17 (1): 11-28.

López Sáez, J. A.; Alba Sánchez, F.; Pérez Díaz, S. y Manzano Rodríguez, S. 2010a: "Paisaje holoceno de una gran urbe: la ciudad de Madrid". Polen: 7-24.

López Sáez, J. A. y Blanco González, A. 2005: “La mutación Bronce Final/Primer Hierro en el suroeste de la Cuenca del Duero (provincia de Ávila): ¿cambio ecológico y social?". En A. Blanco, C. Cancelo y A. Esparza (eds.): Bronce Final y Edad del Hierro en la Península Ibérica. Colección Aquilafuente 86. Salamanca: 229-250.

López Sáez, J. A.; Burjachs, F y López Merino, L. 2006: "Algunas precisiones sobre el muestreo e interpretación de los datos en Arqueopalinología". Polen 15: 17-29.

López Sáez, J. A.; López García, P. y Burjachs, F. 2003: "Arqueopalinología: Síntesis crítica". Polen 12: 5-35.

López Sáez, J. A. y López Merino, L. 2007: “Coprophilous fungi as a source of information of anthropic activities during the Prehistory in the Amblés Valley (Ávila, Spain): the archaeopalynological record". Revista Española de Micropaleontología 39: 103-116.

López Sáez, J. A.; López Merino, L. y Pérez Díaz, S. 2008: "Los vettones y sus paisajes: Paleoambiente y paleoeconomía de los castros de Ávila". En J. Álvarez Sanchís (ed.): Arqueología vettona. La Meseta occidental en la Edad del Hierro. Zona Arqueológica 12, Museo Arqueológico Regional. Alcalá de Henares: 140-152.

López Sáez, J. A.; López Merino, L.; Alba Sánchez, F.; Pérez Díaz, S.; Abel Schaad, D. y Carrión, J. S. 2010b: "Late Holocene ecological history of Pinus pinaster forests in the Sierra de Gredos of central Spain". Plant Ecology 206: 195-209.
López Sáez, J. A. y Pérez Díaz, S. 2012: "Paleoambientes y dinámica antrópica en la Meseta Sur (Madrid) durante la Primera y la Segunda Edad del Hierro". En J. Morín y D. Urbina (eds.): El Primer Milenio a.C. en la Meseta Central. De la longhouse al oppidum 2. AUDEMA S.A. Madrid: 295-304.

López Sáez, J. A.; Van Geel, B.; Farbos-Texier, S. y Diot, M. F. 1998: "Remarques paléoécologiques à propos de quelques palynomorphes non-polliniques provenant de sédiments quaternaires en France". Revue de Paléobiologie 17: 445-459.

López Sáez, J. A.; Van Geel, B. y Martín Sánchez, M. 2000: "Aplicación de los microfósiles no polínicos en Palinología Arqueológica”. En V. Oliveira Jorge (ed.): Contributos das Ciências e das Technologias para a Arqueologia da Península Ibérica. Actas do $3^{\circ}$ Congresso de Arqueologia Peninsular (Vila-Real, Portugal 1999) IX: 11-20. Oporto.

Lorrio, A. 1988-1989: "Cerámica gris orientalizante de la necrópolis de Medellín (Badajoz)". Zephyrus XLI-XLII: 283-314.

Lorrio, A. J. 2008: "Cerámica gris". En M. Almagro Gorbea (ed.): La necrópolis de Medellín II. Estudio de los hallazgos. Bibliotheca Archaeologica Hispana 26 (2), Real Academia de la Historia. Madrid: 673-723.

Moore, P. D., Webb, J. A. y Collinson, M. E. 1991: Pollen analysis. London.

Moreno-García, M. y Pimenta, C. M. 2011: “Animal dung: rich ethnographic records, poor archaeozoological evidence". En U. Albarella y A. Trentacoste (eds.): Ethnozooarchaeology. The present and past of human-animal relationships. Oxbow Books. Oxford: $20-28$.

Nienhuis, J. A. J. H. 2003: "The rediscovery of Spengler's freshwater pearlmussel Pseudunio auricularius (Spengler, 1793) (Bivalvia, Unionoidea, Margaritiferidae) in two river systems in France, with an analysis of some factors causing its decline". Basteria 67(1-3): 67-86.

Ongil, M. I. 1991: "Villasviejas del Tamuja (Botija, Cáceres). El poblado (1986-1990)". Extremadura Arqueológica II: 255-267.

Ortega Blanco, J. y Valle Gutiérrez, M. del 2004: “El poblado de la Edad del Hierro del Cerro de la Mesa (Alcolea de Tajo, Toledo). Primeros resultados". Trabajos de Prehistoria 61 (1): 175-185.

Payne, S. 1973: "Kill-off patterns in sheep and goats: the mandibles from Asvan Kale". Anatolian Studies 23: 281-304.

Pereira Sieso, J. 2008: "La tumba de la Casa del Carpio y el comercio en el Valle del Tajo". En Arqueología Vettona: La Meseta Occidental en la Edad del Hierro. Zona Arqueológica 12, Museo Arqueológico Regional. Madrid: 114-125.

Ramón Torres, J. 1995: Las ánforas fenicio-púnicas del Mediterráneo Central y Occidental. Colección Instrumenta 2, Consell Insular d'Eivissa i Formentera y Universidad de Barcelona. Barcelona. 
Redondo Rodríguez, J. A. y Esteban Ortega, J. 19921993: "El hábitat rural indígena en la provincia de Cáceres: problemática de su estudio". Studia Historica. Historia Antigua 10-11: 161-175.

Rodero, A. 1995: Las ánforas prerromanas en Andalucía. Epigrafia e Antichità 13, Fratelli Lega Editori, Faenza. Bologna.

Rodríguez Díaz, A. y Ortiz Romero P. 2004: El edificio protohistórico de La Mata (Campanario, Badajoz) y su estudio territorial. 2 Vols. Universidad de Extremadura. Cáceres.

Rodríguez Díaz, A. y Pavón Soldevilla, I. 1999: El poblado protohistórico de Aliseda (Cáceres). Campaña de urgencia de 1995. Ayuntamiento de Aliseda. Cáceres.

Rubinos Pérez, A.; Fábregas Valcarce, R.; Alonso Mathias, F. y Concheiro Coello, Á. 1999: "Las fechas de C-14 del Castro de O Achadizo (Boiro, A Coruña): problemática de la calibración de conchas marinas". Trabajos de Prehistoria 56 (1): 147-155.

Ruiz Zapatero, G. y Álvarez Sanchís, J. 2002: "Etnicidad y arqueología: tras la identidad de los vettones". SPAL 11: 253-276.

San Miguel Maté, L. C. 1993: "El poblamiento de la Edad del Hierro al occidente del Valle Medio del Duero". En C. Sanz Mínguez, Z. Escudero Navarro y F. Romero Carnicero (eds.): Arqueología Vaccea. Estudios sobre el mundo prerromano en la cuenca media del Duero. Junta de Castilla y León. Valladolid: 21-66.
Schweingruber, F. H. 1978: Mikroskopische holzanatomie. Swiss Federation Institut for Res. Birmensdorf.

Schweingruber, F. H. 1990: Anatomy of European Woods. Verlag Paul Haput. Berna, Stuttgart, Viena.

Silver, I. A. 1969: "The Ageing of Domestic Animals". En D. Brothwell y E. S. Higgs (eds.): Science in Archaeology. Thames and Hudson. Londres: 283-302.

Strayer, D. L.; Caraco, N. F.; Cole, J. J.; Findlay, S. y Pace, M. L. 1999: "Transformation of freshwater ecosystem by bivalves". BioScience 49: 19-27.

Stuiver, M. y Reimer, P. J. 1993: "Extended 14C database and revised CALIB radiocarbon calibration Program". Radiocarbon 35: 215-230.

Vaughn, C. C.; Nichols, S. J. y Spooner, D. E. 2008: "Community and foodweb of freshwater mussels". Journal of the North American Benthological Society 27: 409-423.

Vernet, J. L.; Ogereau, P.; Figueiral, I.; Machado, C. y Uzquiano, P. 2001: Guide d'identification des charbons de bois préhistoriques et récenos. SudOuest de l'Europe: France, Péninsule Ibérique et Îles Canaries. Centre National de la Recherche Scientifique. Paris.

Wattenberg, F. 1978: Estratigrafía de los cenizales de Simancas (Valladolid). Monografías del Museo Arqueológico de Valladolid 2. Valladolid. 